All102 b55550

NATL INST OF STANDARDS \& TECH R.I.C.

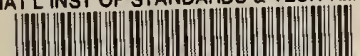

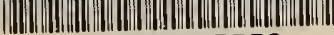

A11102655550

Bukowskl, Richard/An introductlon to it

VU $U$ II OU- 0349

\title{
An Introduction to Fire Hazard Modeling
}

Richard W. Bukowski

U.S. DEPARTMENT OF COMMERCE

National Bureau of Standards

National Engineering Laboratory

Center for Fire Research

Gaithersburg, MD 20899

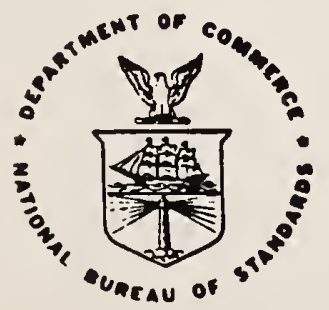

U.S. DEPARTMENT OF COMMERCE

IREAU OF STANDARDS

100

.1156

\#86-3349

1986

c. 2 

NBSIR $86-3349$

\section{AN INTRODUCTION TO FIRE HAZARD MODELING}

Richard W. Bukowski

U.S. DEPARTMENT OF COMMERCE

National Bureau of Standards

National Engineering Laboratory

Center for Fire Research

Gaithersburg, MD 20899

March 1986

U.S. DEPARTMENT OF COMMERCE, Malcolm Baldrige, Secretary NATIONAL BUREAU OF STANDARDS, Ernest Ambler, Director 

List of Tables $\ldots \ldots \ldots \ldots \ldots \ldots \ldots \ldots \ldots \ldots \ldots \ldots \ldots \ldots \ldots \ldots \ldots \ldots \ldots \ldots \ldots \ldots$ v

List of Figures $\ldots \ldots \ldots \ldots \ldots \ldots \ldots \ldots \ldots \ldots \ldots \ldots \ldots \ldots \ldots \ldots \ldots \ldots$

Abstract $\ldots \ldots \ldots \ldots \ldots \ldots \ldots \ldots \ldots \ldots \ldots \ldots \ldots \ldots \ldots \ldots \ldots \ldots \ldots \ldots \ldots \ldots \ldots \ldots \ldots$

1. INTRODUCTION $\ldots \ldots \ldots \ldots \ldots \ldots \ldots \ldots \ldots \ldots \ldots \ldots \ldots \ldots \ldots \ldots \ldots \ldots \ldots \ldots$

2. PREDICTIVE METHODS .............................. 2

3. ALGEBRAIC EQUATIONS ............................. 4

4. APPLICATION OF MODELS ............................ 5

$4.1 \quad$ Fire Models .................................. 5

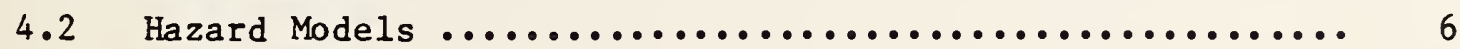

4.3 Risk Models ................................. 7

5. MODELING TECHNIQUES $\ldots \ldots \ldots \ldots \ldots \ldots \ldots \ldots \ldots \ldots \ldots \ldots \ldots \ldots \ldots \ldots \ldots \ldots$

6. DISCUSSION OF AVAILABLE FIRE MODELS .................. 9

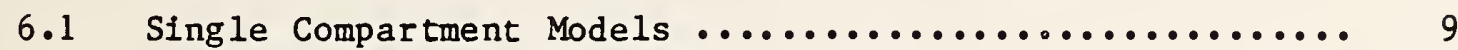

6.2 Multiple Compartment Models ....................... 11

7. MAKING HAZARD ESTIMATES ........................... 13

7.1 Extent of Fire Spread ........................ 15

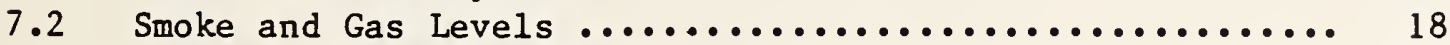

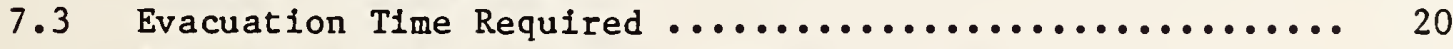

7.4 Estimating Response Time of Detectors and Sprinklers .... 21

8. ASSESSING HAZARD WITH A MODEL $\ldots \ldots \ldots \ldots \ldots \ldots \ldots \ldots \ldots \ldots \ldots \ldots \ldots \ldots \ldots \ldots . \ldots \ldots$

8.1 Combustion ................................. 23

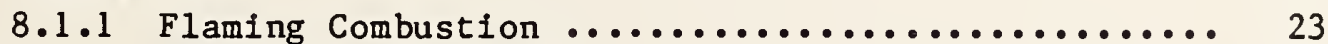

8.1.2 Smoldering Combustion ...................... 24

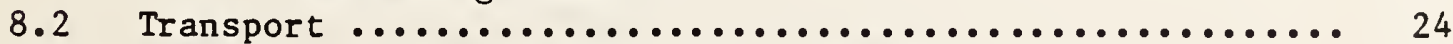

8.3 Effect on Occupants (Tenability Limits) $\ldots \ldots \ldots \ldots \ldots \ldots \ldots$

8.4 Fire Protection Systems/HVAC ..................... 29

8.4.1 Modeling Fire Protection Systems ............. 30

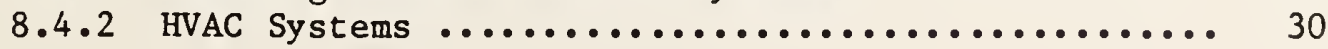

9. VALIDATION $\ldots \ldots \ldots \ldots \ldots \ldots \ldots \ldots \ldots \ldots \ldots \ldots \ldots \ldots \ldots \ldots \ldots \ldots \ldots \ldots \ldots \ldots$

10. MANAGING THE OUTPUT ............................ 32 


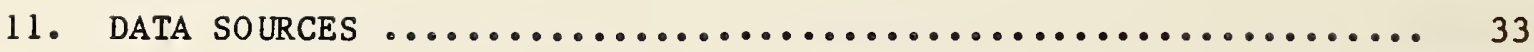

11.1 Equivalence Ratio ........................... 35

12. THE APPLICATION OF HAZARD ANALYSIS $\ldots \ldots \ldots \ldots \ldots \ldots \ldots \ldots \ldots \ldots$

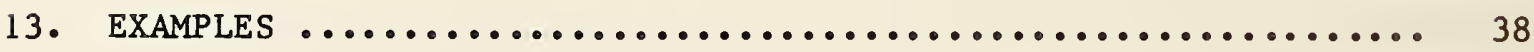

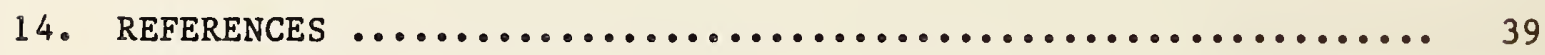

APPENDIX A. Toxic Hazard Evaluation of Plenum Cables .......... 53

APPENDIX B. Evaluation of Furniture Fire Hazard Using a Hazard Assessment Computer Model ........................6 69 


\section{LIST OF TABLES}

Page

Table 1. Single Compartment Models ...................... 42

Table 2. Multiple Compartment Models ..................... 43

Table 3. Material Property Data ........................... 44

Table 4. Thermal Properties of Room Lining Materials ........... 46 


\section{LIST OF FIGURES}

$\underline{\text { Page }}$

Figure 1. Relationship between peak mass loss rate and ignition distance for various ignitability levels

Figure 2. Room flashover modeling prediction for various ventilation factors (gypsum wall lining/2.4 m ceiling height)

Figure 3. Time to fill to the level of the fire - Q in $\mathrm{kW}$

Figure 4. Interrelationships of major components of a fire hazard model

Figure 5. Equivalence ratio - propane

Figure 6. Equivalence ratio - toluene 
AN INTRODUCTION TO FIRE HAZARD MODELING

Richard W. Bukowski

Abstract

An overview of the development and current capabilities of predictive methods for fire hazard analysis is provided. This includes a range of methods from simple, algebraic equations to complex, computer simulation models. In each case the form, major simplifying assumptions, calculated parameters, and limitations will be discussed. The specific application of these predictive methods to hazard analysis, and the availability of the data resources necessary to conduct a hazard analysis is described. Information on the use of a number of available models, with particular emphasis on those which can be used on desk-top computers, is provided. A discussion of the predictive accuracy of selected models is included. Some examples of hazard analyses using these methods are presented.

Key words: computer models, equations, fire models, hazard assessment, toxicity.

\section{INTRODUCTION}

Traditionally, the practice of fire protection engineering has involved the application of expert judgement and experience to current problems. This is largely accomplished through the development and use of prescriptive codes, standards, and manuals of practice through a consensus process, by committees made up of such experts. While this system has served us reasonably well in the past; it is not without its weaknesses. 
These committees, and the codes which they develop, tend to deal well with traditional problems since they are founded in traditional experience, both with actual fires and with fire tests. More recently, however, technology and materials science have been changing rapidly such that more and more decisions must be made by these committees and by enforcing authorities in the absence of any experience or historical precedent upon which to make such decisions. This situation generally leads to extreme conservatism and redundancy leading to increased cost, at least until experience is gained with the new technique or material. Additionally, toxicity concerns particularly associated with the growing use of synthetic materials, need to be addressed within the context of the overall hazard of fire.

A potential solution to this problem rests in the development of predictive methods which will allow performance based codes by providing a practical mechanism for evaluating the impact of new technology or materials without the necessity for conducting extensive, and prohibitively costly fullscale experimental analyses.

The purpose of this paper is to provide an overview of some of the predictive methods which are currently avallable to practicing engineers for conducting quantitative fire hazard analyses.

\section{PREDICTIVE METHODS}

The current fire-related prediction tools have been developed as a direct result of fire research conducted around the world and the avallability of low $\cos t$, high performance computers. In general, the ability to predict a given 
fire phenomenon begins with well-designed experiments. Analysis of the data from these experiments produces an empirical understanding of the interrelationship of important variables.

Through the application of the principles of physics, chemistry, fluid mechanics, etc., the process of interest can be described completely in terms of basic properties and physical constants. This represents a phenomenological understanding of the process and a mathematically self-consistent description of it.

The form of the currently-available predictive tools covers a range from simple, algebraic equations through highly complex computer models involving ordinary or partial differential equations. At the simplest end, algebraic equations (generally semi-empirical) have been derived for many processes and are suitable for estimation purposes since they generally deal with steadystate phenomena. Since fire is a highly dynamic process, these steady-state solutions represent inexact but useful techniques for engineering purposes.

Since the presence or absence of safety to a'structure or its occupants is highly time-dependent, times to events are of fundamental importance. But the time dependent form of the equations governing a fire related process is generally too complex for hand-calculated solutions. Therefore, fire models have been developed which use the computer to solve these time dependent equations.

Most such computer fire models solve sets of ordinary differential equations as a quasi-steady-state approximation. That is, the transient 
solution results from a series of short time intervals over which the process is considered to be steady-state. If the selected time intervals are short enough (of the order of fractions of a second) the assumption of a steadystate process over this short time interval is a good one.

In order to provide a full transient type analysis, one needs to solve a set of partial differential equations for the process of interest. While this is done in some models, it is usually not practical for engineering purposes since the time required for solution, and the computer necessary to solve all of the partial differential equations for even a simple case is impractical for most engineering-related problems. These models do serve a very useful purpose within the research community, however, in that they provide insight into the most basic levels of the physics and chemistry of the process.

\section{ALGEBRAIC EQUÁTIONS}

As stated earlier, a number of algebraic equations suitable for hand calculation have been developed for some specific fire-related processes. Many of these equations have been compiled in a report by Lawson and Quintiere [1] , along with a detailed discussion of their use and limits of applicability. Due to the self-explanatory nature of this report, it w1ll not be discussed in detail here. It should be pointed out, however, that Nelson [2] has put most of these equations into a computer program which can be operated on a small desk top computer. This program is not a fire model since it solves each equation independently. Rather, it represents a simplification of use of the included equations.

Numbers in brackets refer to the literature references listed at the end of this report. 


\section{APPLICATION OF MODELS}

A model is any set of equations which mathematically represents some physical process. Thus, a model describes what is likely to occur as the process being modeled proceeds. The widespread availability of powerful computers has resulted in the development of models for many complex phenomena. For example, climate modeling forms the basis for most weather predictions done today. These climate models are made up of mathematical expressions for such forces as solar heating and the earth's rotation which cause the development and movement of weather patterns across the earth. In a similar fashion, fire models contain equations which describe the processes of combustion, heat transfer, and fluid flow produced by a fire within a specific geometry.

\subsection{Fire Models}

Fire models predict the environmental conditions within one or more physically bounded spaces as a result of fire contained therein. They predict how much heat, smoke, and gases are produced by the fire and how each of these quantities is distributed through the building over time. Some important points about fire models as they currently exist must be understood in order to appreciate their capabilities and application.

Most current fire models have been developed for specific purposes such as to describe a single phenomenon (filling of a compartment) or a specific application (aircraft interior fires) rather than for general use. Fires involve many highly complex phenomena and no single fire model describes all 
of these phenomena to the same level of detail. Within a given model, specific phenomena may be described empirically, semi-empirically, by partial or complete physics, or may not be included. The level of detail included for any specific process depends both on the level of technical understanding of the process available at the time the model was written and on the specific purpose for that model. Thus, a user must understand the individual model's range of validity and how that applies to the purpose for which the model is being used.

\subsection{Hazard Models}

A hazard model is one which predicts the consequences of an exposure to a specified set of conditions over time. Thus, a hazard model uses the information on the conditions produced by the fire over time from the fire model and evaluates the impact of these conditions on that which was exposed. In most cases, the hazard of interest is that to occupants of the building. But hazard models could also be used to evaluate property damage as a result of the fire.

Hazard is scenario dependent. That is, hazard must be evaluated for a single, specified set of conditions involving a specific fire in a specific building with a specific set of occupants and their associated physical capabilities. 


\subsection{Risk Models}

Risk models predict the cummulative threat posed by all possible hazardous events (scenarios) weighted by their probability of occurrence. Thus an event which is very hazardous but relatively unlikely to occur would be similar in risk to an event which is less hazardous but more likely to occur.

From the above, it can be seen that fire models form the phenomenological base for hazard models, and hazard models for risk models. For engineering purposes for the evaluation of potential impact or benefits of product design changes, material selection, or other hazard migation strategies, hazard models would be the most appropriate. However, eventually, some consideration of risk will have to be made. This is because changes which reduce the hazard for one scenario may potentially result in increased hazard from some other scenario. Depending on the probability of occurrence, the overall benefit could be either positive or negative. An example of this might be that a flame retardant which would reduce the hazard from flaming ignitions might also promote the propensity of a material to smolder and increase the hazard from smoldering ignitions. Depending on the relative probabilities of smoldering and flaming ignitions for the product, the overall risk associated with that product might be increased or decreased accordingly.

\section{MODELING TECHNIQUES}

There are three general categories of fire modeling techniques; field models, zone models and network models. 
Field models divide a space into a 1, 2, or 3-dimensional network of relatively fine elements and, using the governing partial differential equations of the phenomena of interest, calculate the conditions in each element as a function of time. These models provide very high resolution and detail but are computationally intensive; a simple combustion problem in a single compartment requiring a significant time on the largest super computer. Thus, they represent an excellent research tool but generally are not as yet too practical for problem solving.

Zone models divide each compartment into a small number of volumes, including at a minimum an upper layer, a lower layer and a fire plume region. These models work well in the compartments nearest the fire where stratified conditions exist because of the significant driving force of buoyancy. The turbulence normally associated with fires causes mixing within the layers which leads to conditions that are reasonably replicated by the uniform layer approximation of the zone models. These models are more computationally simple than field models and, given a numerical routine to solve the equations, can run multiple compartment simulations in real time on a mid-sized computer.

Network models assume that compartments are uniform in space. These models can be used to solve problems involving very large numbers of nodes (compartments) efficiently. At some distance from a fire, products are well mixed and are driven by the now-dominant forces of HVAC, stack effect, and wind. Network models are therefore well suited to the realm at some distance from the fire source. 
From this, it is clear that the most effective approach for treating the problem at hand is to marry these three techniques into a hybrid model which can provide the detail necessary for useful hazard predictions while maintaining practicality for problem solving. In fact, this is probably the only approach with enough computational efficiency to be used for predictions in large structures due to the large numbers of compartments therein. Thus, the direction of the work at CFR in hazard model development is to use the zone model for the near-fire compartments where buoyancy and stratification are the key phenomena. This model would include field model-type elements in special zones, as required (e.g., the zone which represents the ceiling material, where transient heat conduction requires a field equation analysis). Once beyond the distance where stratification is significant the network technique will be used to map the distribution of products in the rest of the structure.

\section{DISCUSSION OF AVAILABLE FIRE MODELS}

In addition to the categories of field, zone, and network models which relate to the number of spaces into which each compartment is divided for solution, fire models can also be categorized as single compartment models or multiple compartment models relating to the number of rooms in the structure to be analyzed.

\subsection{Single Compartment Models}

By far, most currently existing fire models are single compartment models. Some of the more common single compartment models are shown in Table 1. These models range from very simple such as ASET (Available Safe Egress 
Time) [3] which is intended to estimate the upper layer temperature and filling time for a fire in a single compartment, and COMPF2 (Computation of Post Flashover Model 2) [4] which calculates only post-flashover temperatures and flows, to Harvard V [5] and OSU (Ohio State University) [6] which contain relatively complex phenomena and predict numerous aspects of a time dependent room fire. The Cal Tech (California Institute of Technology) model [7] is a filling model similar to ASET, and DACFIR (Dayton Aircraft Cabin Fire Model) [8] is designed to model a fire involving the seating of a commercial aircraft over only the first 5 to 10 minutes after ignition.

While each of these models has appropriate applications, only the Harvard $\mathrm{V}$ and OSU provide sufficient detail for a rigorous hazard analysis. The OSU code was developed by Smith at Ohio State University expressly for the purpose of extending measurements taken in the OSU calorimeter (ASTM E906) to compartment fire predictions [9]. Thus, the utility of this model is generally limited to cases where data from the OSU calorimeter is available on the material in question. The Harvard code, however, is more general purpose and will be more generally applicable. Currently, there are several versions of the Harvard V Code available. These versions, identified as 5.1, 5.2, 5.3, etc. represent modifications for the inclusion of extensions by specific researchers. For example, 5.2 and 5.3 both contain vent mixing and contamination of the lower layer not included in 5.1. CFR is currently working on the assemblage of a "standard" version of Harvard $V$ containing all applicable extensions. When completed and fully documented this will be the model of choice for single room calculations, particularly when it is destred to include combustion phenomena. 


\subsection{Multiple Compartment Models}

Models which calculate the transport of energy and mass through multiple compartments of a structure are a relatively recent development. The three currently available are listed in Table 2. The Building Research Institute (BRI or Tanaka) [10] and Harvard VI [11] models were published in 1983 and the initial version of FAST (Fire and Smoke Transport) [12] was released one year 1ater .

The BRI model can be used to predict the distribution of fire products in an arbitrary number of compartments on multiple floors. It contains a relatively simple combustion algorithm for steady-state combustion. Two major drawbacks of this model involve the lack of vent mixing and a cumbersome solution algorithm for solving the compartment to compartment transport.

The lack of vent mixing means that all energy and mass released by the fire is retained in the upper layers of each compartment. Thus, temperatures, smoke, and gas levels in the upper layer are over-estimated and the rate of filling of each compartment is slower than would be experienced in real life. The solution algorithm for transport is cumbersome because the user must specify the order in which fire products will enter each compartment. For compartments in a straight line this is obvious; but for complex geometries this often leads to failures of the model in reaching a solution (convergence).

Harvard VI is multi-compartment extension of Harvard 5.1. As with the BRI code, Harvard VI does not currently contain vent mixing. In addition, the 
current version of Harvard VI can only handle three compartments. The model was initiated near the end of the Center for Fire Research Program at Harvard, and was not completed prior to the retirement of Dr. Emmons. Dr. Morita from Science University of Tokyo worked on Harvard VI during a one year guest worker assignment at CFR. During his stay, he got the program running, but there are still some subroutines which do not work. At present there is no official released version of Harvard VI (although there is a report on the mode1).

FAST is the most widely distributed and used multi-compartment model. FAST does contain vent mixing and has a reliable, robust equation solver which does not require any unusual user setup. The first released version (version 16) can calculate any number of compartments on a single floor. Version 17 , released in the fall of 1985, includes vertical shafts and thus can handle multiple floors.

FAST has little combustion within it, requiring that the fire be entered in terms of a mass loss rate, heat of combustion, and species yields. It accepts this data in the form as produced by the furniture calorimeter [13] or cone calorimeter [14]. Where more detailed combustion is needed as input, such as multiple items burning, it is possible to use Harvard $V$ to predict the combustion phenomena and then enter the energy and species release rates predicted by Harvard $V$ into FAST for the remainder of the calculation. Version 18 will include improved combustion, and the upholstered furniture combustion model of Deitenberger [15] will be incorporated into a future version of FAST. These changes will allow a broader range of applicab1l1ty for FAST in that it will be able to calculate the changes in burning rate and 
species yields as a function of the surrounding compartments, as opposed to its current "free burning" assumption.

\section{MAKING HAZARD ESTIMATES}

The basic steps in making hazard estimates can be illustrated within the context of a simple, hand calculated estimating procedure suggested by the NFPA Toxicity Advisory Committee. While more refined procedures would be expected to produce more quantitative results, such simple procedures can be valuable in providing initial guidance with regard to the magnitude of the toxic hazard posed by a new material or use.

The steps necessary to conduct such an analysis would include:

(1) Define the proposed use and $\operatorname{context(s)}$ of use.

(2) Outline scenario(s) of concern.

(3) Collect pertinent test data and algorithms.

(4) Estimate hazard development.

(5) Estimate occupant response time needs.

(6) Estimate possible mitigating effects of fire protection systems .

The proposed use and context of use includes the physical form of the material, quantity, and location within the structure.

The scenarios of concern should be specified in as much detail as possible and should include "typical" as well as "worst" cases. 
Hopefully, some test or material property data is available. Sometimes, data from similar materials might be used to obtain performance estimates. In a regulatory context, a code authority can require the proposer to submit the required data before action can be taken on the proposal.

The hazard development involves two areas. The material may result in a fire which develops faster or spreads farther, and/or it may result in more or "worse" smoke. All fires produce heat, smoke, and toxic gases, so the key issue here is estimating the incremental change resulting from the material (product) in question and then assessing the significance of this change in terms of occupant safety.

Occupant response time needs should be evaluated for various "typical" cases of occupant load, location, and physical/mental capabilities.

In evaluating the impact of fire protection systems, the "base case" should include only mandatory features. Provision of additional features may be suggested/evaluated to mitigate any increase in hazard identified with the use of the "new" material and form the basis for exceptions to any limitations imposed.

The following presents some potentially useful data and relationships for addressing steps 4 through 6 that provides "order of magnitude" estimates for the important parameters involved in a hazard analysis. This materlal has been assembled from various sources and, in some cases, simplifled with the goal of providing estimates rather than exact solutions. Materfal property data for use in the calculations is presented in table 3. Test data from 
upholstered furniture burns (peak heat release rates, time to peak, and heat of combustion) along with a simple formula to estimate peak heat release rate and time to peak for upholstered furniture items (correlated to the items tested) are presented in reference 19 by Babrauskas. Smoke yield ( $Y_{s}$ ) values for these items can be taken as 0.03 for thermoplastic fabrics over polyurethane foam, 0.005 for cotton fabric over cotton batting, and 0.015 for all others. The smoke yield is the mass of smoke produced per unit mass consumed. The $\mathrm{LC}_{50}(30 \mathrm{~min})$ for all construction types can be taken as $32 \mathrm{mg} / \mathrm{l}$. This is the mass concentration (fuel mass divided by the volume into which the combustion products are distributed) necessary to kill $50 \%$ of the test animals exposed for 30 minutes.

\subsection{Extent of Fire Spread}

The first question to be answered is whether the fire will remain in the first item ignited or will it spread to other combustibles. Any combustibles so located as to experience direct flame impingement from the first item should be assumed to ignite. We next estimate the potential of spread by radiative transfer. For each item involved by direct contact we assign a $\dot{Q}$, an estimate of the average heat release rate, and a $\Delta_{c}$, an effective heat of combustion. For $i$ items burning together we estimate the combined mass loss rate from:

$$
\dot{\mathrm{m}}_{\text {total }}=\sum_{1} \frac{\dot{\mathrm{Q}}_{1}}{\Delta \mathrm{H}_{c_{1}}}
$$

Figure 1 will now allow us to estimate whether nearby objects will ignite. Note that this does not involve a direct calculation of radiation, but rather uses an empirical correlation developed by Babrauskas as cited on figure 1. 
Another spread mechanism is flashover, which will involve all combustibles in the room. To estimate whether the room will be driven to flashover, we calculate the ventilation factor (vent area times square root of vent height) and sum the heat release rates of all items burning. Figure 2 can then be used to determine the minimum energy necessary to flash over a room of a given floor area for a specified ventilation factor. Alternately, the equation from Thomas for minimum required flashover energy ( $k W$ ) may be used.

$$
\dot{Q}_{\text {fo }}=378 \mathrm{~A}_{\mathrm{v}} \sqrt{\mathrm{h}_{\mathrm{v}}}+7.8 \mathrm{~A}_{\mathrm{w}}
$$

Source: Fire and Materials, Vol. 5, No. 3, 103-111, Sept. 1981.

where: $A_{v}$ is the vent area $\left(m^{2}\right)$,

$h_{v}$ is the vent height $(m)$, and

$A_{w}$ is the total wall area $\left(m^{2}\right)$.

If the combined heat release rate exceeds the minimum flashover energy for the compartment, all combustible items (which decompose below $\sim 1000^{\circ} \mathrm{C}$ ) must be assumed to pyrolyze.

A final mechanism of material involvement is immersion in the hot gas layer. The temperature of the layer can be estimated from the following equation :

$$
\mathrm{T}_{\mathrm{UL}}=6.85\left[\frac{\sum_{i} \dot{Q}_{i} 2}{\left(\mathrm{~A}_{\mathrm{v}} \sqrt{\mathrm{h}_{\mathrm{v}}}\right)\left(\mathrm{h}_{\mathrm{k}} \mathrm{A}\right)}\right]^{1 / 3}+\mathrm{T}_{\mathrm{amb}}
$$

Source: NBSIR $83-2712$ 
where: $\sum \dot{Q}_{i}$ is the combined heat release rate $(k W)$,

i

$A_{v} \sqrt{h_{v}}$ is the ventilation factor,

$A$ is the total enclosure surface area $\left(\mathrm{m}^{2}\right)$,

$h_{k}=k / \delta^{*}$, $k$ is the thermal conductivity (table 4 ), and

$\delta$ is the thickness (m) of the lining material.

Note: if multiple lining materials are present $\sum\left(h_{k} A\right)_{1}$ should be used. $\mathrm{T}_{\text {amb }}$ is the ambient temperature $\left({ }^{\circ} \mathrm{C}\right)$

This will tell us if any materials immersed in the hot gas layer can be heated enough to decompose or ignite. If the previous flashover prediction showed no flashover and this calculation shows additional material ignites, the additional heat release rate should be added to the previous total and a new flashover prediction made. Equation 3 should only be used for cases where the combustion is not ventilation-limited (pre-flashover).

At this point, we have an estimate of the extent of spread of fire within the compartment of origin. If flashover is expected, and if there are combustibles in the next compartment we must probably assume that the fire will spread to it, and so on, until a closed, fire-rated partition is encountered. This leaves little time for evacuation from these compartments.

\footnotetext{
*Use this form for steady state (long time) calculations. This gives the most conservative result. For shorter times, the initial heating solution is obtained by using $h_{k}=\sqrt{k \rho c / t}$. The $k \rho c$ product for common materlals is given in table 4. An estimate of the time beyond which the long time form is valid is given by $t_{p}=(\rho c / k)(\delta / 2)^{2}(\mathrm{sec})$.
} 


\subsection{Smoke and Gas Levels}

The next step is to estimate the impact of smoke and toxic gases on the occupants of any compartments freely connected to the compartment of origin. We can estimate the filling time for the compartment of origin from the total heat release rate previously computed and figure 3. (Note: this figure is for a constant output fire). The filling time for freely connected compartments on the same floor will be of the same order of magnitude (use the total floor area).

For most fuels burning with sufficient oxygen, the smoke yield (fraction of fuel mass burned which is converted to smoke) is a constant, $\left(Y_{S}\right)$, which varies over a range of a few tenths of a percent (for wood and cellulosic fueis) to about $30 \%$ (for some plastics).

We can estimate the smoke density in all compartments if we have the mass fraction of fuel converted to smoke $\left(Y_{S}\right)$ for each fuel. For 1 fuels we $f$ ind:

$$
M_{S}=\frac{\sum\left(m_{f} Y_{s}\right)_{1}}{V_{T}}
$$

where: $m_{f}$ is the total mass of fuel $i$ burned in milligrams, and $\mathrm{V}_{\mathrm{T}}$ is the total volume of all freely connected compartments in $\mathrm{m}^{3}$.

$M_{S}$ gives a soot mass concentration in each compartment once filled (assuming full mixing). Then, using the relation that a mass concentration of one mil1gram per cubic meter (of black smoke) has an optical density of .0035 per meter, an optical density can be obtained $\left(D=M_{S} / 0.0035 \mathrm{~m}^{-1}\right)$. Finally, using the relation from Rasbash: 


$$
V=1.4 / D^{.767}
$$

where: $V$ is distance of vision (m),

$D$ is optical density per meter,

we can estimate how far an occupant can see.

In the same manner as for smoke, the toxicity of the combustion products in each compartment can be estimated by:

$$
c_{c p}=\sum_{i} \frac{\left(m_{f}\right)_{i}}{V_{T l}}
$$

where: $\left(m_{f}\right)_{1}$ is the total mass of fuel 1 burned (mg), $\mathrm{V}_{\mathrm{T} \ell}$ is the total volume of all compartments in $\ell\left(1000 \ell=1 \mathrm{~m}^{3}\right)$,

In this case a $Y_{c p}$ similar to the $Y_{s}$ is not included since the conversion efficiency is taken into account in the $\mathrm{LC}_{50}$ determination (Note the change in units for volume). $C_{c p}$ gives the "combustion product" concentration in each compartment. If we then take the ratio of $\mathrm{C}_{\mathrm{cp}}$ to the mass weighted average $\mathrm{LC}_{50}$ for each fuel we have the fraction of the $30 \mathrm{~min}$. lethal concentration in each compartment. That is :

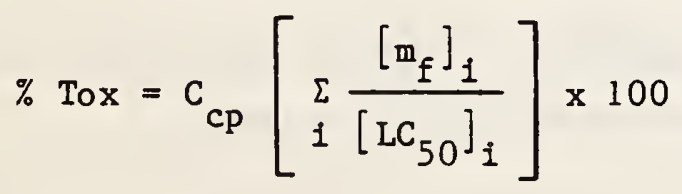

The summation term in brackets in equation 7 is a way of determining an average $\mathrm{LC}_{50}$ for a mixture of fuels for which the $\mathrm{LC}_{50}$ of each individual fuel is known. After calculating the percent toxicity by equation 7 , we can apply 
the assumption (Haber's rule) that the product of concentration and time is a constant $\left(\mathrm{C}_{\mathrm{cp}} \Delta t=\mathrm{LC}_{50} \cdot 30 \mathrm{~min}\right) . \quad$ Thus, $50 \%$ of the $30 \mathrm{~min}$ lethal concentration is lethal in $60 \mathrm{~min}$ and $150 \%$ of the 30 min lethal concentration is lethal in 20 min.

\subsection{Evacuation Time Required}

The previous sections give an estimate of the development of hazardous conditions within the fire zone. To determine whether this represents a threat to the occupants in these spaces, it is necessary to obtain an estimate of the time required to evacuate these spaces. For any occupant, this time can be estimated from

$$
\Delta t_{\text {evac }}=\Delta t_{\text {notif }}+\sum_{i}\left(\Delta t_{\text {travel }}+\Delta t_{\text {door }}\right)_{1}
$$

where: $\Delta t_{\text {evac }}$ is the total time required from start to a safe point (e.g., horizontal exit or stairwell,

$\Delta t_{\text {notif }}$ is the time from ignition to when the occupant finds out there is a fire,

$\Delta t_{\text {travel }}$ is the travel distance from start to the opening to the next compartment divided by a characteristic walking speed,

$\Delta t_{\text {door }}$ is the time spent waiting to move through the door to the next compartment, and 
ceilings, smoke detectors will activate in about one minute, heat detectors and fast response sprinklers in about three minutes and standard sprinklers in about six minutes. If estimates of heat release vs time for the early stage of the fire is available, closer estimates of operating times can be made by assuming that a smoke detector will respond when $\dot{Q}=200 \mathrm{~kW}$, heat detectors and fast response sprinklers at about $400 \mathrm{~kW}$, and standard sprinklers at about $600 \mathrm{~kW}$.

For detectors and sprinklers, the activation time defines $\Delta t_{\text {notif }}$ for all occupants not in the room or origin unless the time for the first occupant of the room of origin to reach the compartment in question is less. It should be assumed that detectors will not effect the fire growth or smoke and gas transport. Sprinklers will stop the spread of the fire, reduce the upper layer temperature in all compartments, and limit further addition of smoke and gas mass to the volume, but will mix the smoke and gas present into the entire connected volume.

\section{ASSESSING HAZARD WITH A MODEL}

The major components of a hazard assessment model are shown in Figure 4. Each of these components is currently being addressed in the CFR program and exist in various stages of development.

Details on the current status, capabilities, and limitations of the component models shown in Figure 4 are beyond the scope of this report. The following sections will discuss factors necessary for the current use of models to assess occupant hazard from consumer products; particularly upholstered furniture and mattresses. 


\subsection{Combustion}

Within the hazard model, the combustion process represents the primary source term. That is, it describes the release rates of energy, smoke, and gas species. As shown in the left main block of Figure 4 and as discussed earlier, the combustion process can be described as a specified fire using the data produced by small- or large-scale burns of the product, or can be calculated using a combustion model. For the particular case of upholstered furniture and mattresses, a considerable bank of data exist, largely from CPSCsponsored work at NBS. Since the bulk of this data was taken in conjunction with the development of the oxygen consumption calorimeters and since the specified fire input to the model was tailored to accept the data from these calorimeters, there should be no need to resort to the more complex procedure of using the combustion model for hazard analysis involving these products unless the scenario to be studied involves multiple items burning.

\subsubsection{Flaming Combustion}

Most of the data available in these product categories involves flaming combustion. Significant quantities of small- and large-scale calorimeter data are available on individual materials [16], fabric/filling combinations [17], mock-ups [18] and complete items [19]. Data from room experiments are also available [20]. Most of the data, however, was taken under "free-burning" conditions with adequate ventilation for complete combustion. Thus, the ability to model precisely post-flashover release rates may currently be limited. Design modifications to the cone calorimeter to allow the measurement of energy and species release rates under post-flashover combustion conditions have already been initiated. 
$i$ is the number of compartments between the person's starting point and the safe point.

To estimate these times, the following procedure can be used. In establishing the original scenario, a number of occupants should be assigned to each compartment, and a floor plan with dimensions and door locations should be prepared. For persons in the room of origin, $\Delta t_{\text {notif }}=0$ (unless the fire is in a concealed space). For persons in spaces through which others will evacuate, $\Delta t_{\text {notif }}$ is the time that the first person from the fire space reaches that space. If detectors are present $\Delta t_{\text {notif }}$ is the estimated detector response time for persons not in the space of origin.

For estimating $\Delta t_{\text {travel }}$, walking speeds of $200 \mathrm{ft} / \mathrm{min}$ at a population density of $20 \mathrm{ft}^{2} /$ person or greater and $100 \mathrm{ft} / \mathrm{min}$ at a density of $5 \mathrm{ft}^{2} /$ person or less can be used.

For $\Delta t_{\text {door }}$ use a pass-through rate of one person per second for each $2 \mathrm{ft}$ of opening width (subtract $\mathrm{I} f \mathrm{f}$ from the width if there are doors) or one person per second for a revolving door.

\subsection{Estimating Response Time of Detectors and Sprinklers}

To estimate possible mitigating effects of fire protection features, the key parameter is the response time of the actuating device. While this will be a function of the fire growth rate, room size, ventilation parameter, and device characteristics, for most flaming fires of practical interest some simple estimates can be made. At recommended spacings in rooms with $8-10 \mathrm{ft}$ 


\subsubsection{Smoldering Combustion}

Significantly less data are available on energy and species release rates from smoldering combustion in upholstered furniture and mattresses. While a large number of smoldering experiments have been conducted they have focused primarily on the aspects of smolder propensity (ignition probability) and have not involved the key analytical measurements necessary to specify the energy and species release rates. In the case of smoldering, since radiation (which does not scale) is not important, the data necessary to describe the process can be readily obtained through bench-scale experiments. Simply running a cigarette ignited crevice mockup test (as used by the state of California) in the cone calorimeter without any externally applied flux would provide the necessary data.

The most difficult aspect of modeling smoldering combustion in either upholstered furniture or mattresses would involve predicting the transition from smoldering to flaming. Since the trigger mechanism is not understood it is not currently possible to predict its occurrence with confidence. Thus, the best that one could do would be to (somewhat) arbitrarily select a transition time based on experience.

\subsection{Transport}

Version 16 of FAST, can be used to predict the distribution of energy and species throughout multiple compartments on a single floor. Version 17, released in the fall of 1985 , Includes a vertical shaft allowlng mult1-floor calculations. This shaft is described as a tall room in which an upper layer 
forms and fills the compartment in the same manner as other compartments are modeled. While this is a good approximation for open shafts such as elevator or utility shafts, considerably more detail must be included before stairwells can be adequately modeled. Since the initial focus will be on residential occupancies, this should not pose a major problem for the present. Of particular importance to this issue is the fact that a two story test facility is currently under construction in the CFR Fire Test Building which will simulate a townhouse, complete with stairway. With the addition of this facility and the research planned for it, studies of floor-to-floor transport in such a structure will be forthcoming along with the necessary revisions and improvements to the model to better describe these phenomena.

\subsection{Effect on Occupants (Tenability Limits)}

Most researchers agree that processes of biological response are less exact and understood than the physical sciences.. Thus the methods currently available to address exposure-response are crude. Initial efforts (e.g., as currently provided in FAST) involve the definition of critical concentrationtime products using the NBS toxicity protocol, referred to as species CT.

For each fire interval the fraction of fuel mass which is converted to "toxic" combustion products is entered. Since, in the NBS protocol, the $\mathrm{LC}_{50}$ is defined as the total fuel mass loaded into the furnace divided by the exposure chamber volume, where NBS protocol data is used for analysis, this conversion fraction is defined as unity. 
The species CT calculated by the model then represents the mass concentration of fuel vapors in the upper layer of each compartment integrated over time. The units are $\mathrm{mg}-m i n / 1 i t e r=g r a m-\min / \mathrm{m}^{3}$. To determine a critical value for CT (called $\mathrm{CT}^{*}$ ), take the $\mathrm{LC}_{50}$ for the fuel material, multiplied by the exposure time over which the $L_{50}$ was determined. For example, if the fuel is PVC undergoing flaming combustion, the $L C_{50}=17.3 \mathrm{mg} / 2$ for a 30 min exposure. Thus $\mathrm{CT} *=17.3 \times 30=519 \mathrm{mg}-\mathrm{min} / \mathrm{l}=519 \mathrm{~g}-\mathrm{min} / \mathrm{m}^{3}$. When $\mathrm{CT}=\mathrm{CT} *$ for the fuel, a lethal condition is considered to exist. Note that, since the 30 min $L_{50}$ for most common fuels is in the range $20-40 \mathrm{mg} / \ell$, a CT* value of approximately $900 \mathrm{mg}-\mathrm{min} / \ell$ could be generally applied for estimating purposes where a specific value for the fuel is unknown. Likewise since CT* values for incapacitation are often of the order of $1 / 2$ the value for lethality, a value of $450 \mathrm{mg}-\mathrm{min} / \mathrm{l}$ might be used.

It should be noted that this evaluation procedure assumes the $\mathrm{CT}$ product which causes a biological effect is a constant (referred to as Haber's Rule). Recent data indicate that this is not generally true, but it is the best approximation which can currently be made with available toxicity data. If $\mathrm{LC}_{50}$ data are available for different exposure times for the fuel in question, the Fractional Effective Dose (FED) procedure described by Hartzell et al. [21] can be used to correct the CT* estimate.

Where the fuel consists of a mixture of materials for which LC $_{50}$ data are available for each, an effective $\overline{\mathrm{LC}}_{50}$ (and thus an effective $\overline{\mathrm{CT}}^{\star}$ ) can be determined by the following equation [22]: 


$$
\frac{1}{\overline{\mathrm{LC}}_{50}}=\sum_{i} \frac{(\mathrm{mf})_{i}}{\left(\mathrm{LC}_{50}\right)_{i}}
$$

where: $(\mathrm{mf})_{i}$ is the fraction of total fuel mass represented by material $i$, and

$\left(\mathrm{LC}_{50}\right)_{i}$ is the $\mathrm{LC}_{50}$ (generally for a $30 \mathrm{~min}$ exposure) of material $i$

Then

$\overline{\mathrm{CT}}^{\star}=\overline{\mathrm{LC}}_{50} \times 30 \mathrm{~min}$

If IC $_{50}$ (concentration necessary to incapacitate), or $\mathrm{EC}_{50}$ (concentration necessary to produce any specified effect) data are available, they would be used in exactly the same way to produce a CT* and predict time to incapacitation or other effect.

Another advantage of this method is that the predicted CT value can easily be corrected to account for the fact that the exposure only begins when the person is exposed to the upper layer. If, for example, it is assumed that the exposure begins when the interface reaches 5 feet $(1.5 \mathrm{~m})$ from the floor (nose level of a standing person), it is only necessary to determine the value of CT at this time, and subtract this value from all subsequent values of CT to provide the corrected results. This is because $C T=\int_{0}^{t} C(t) d t=\int_{0}^{t^{\prime}} C(t) d t+$ $\int_{t^{\prime}}^{t} C(t) d t$, where $t^{\prime}$ is the time for the interface to reach the desired $t^{\prime}$ position. 
While this provides a starting point, it is insufficient in the long term since it does not describe such important factors as the cause of the observed effect, variations in uptake rate as a function of activity, or the effect of a varying concentration of individual species components which may change with time or distance from the combustion site due to reaction or loss to surfaces. Additionally, animal experiments conducted to date have not clearly demonstrated how sublethal effects such as incapacitation and exposure to irritants can be reliably included in the predicted exposure-response. These are clearly important factors for which some algorithms mst be developed.

To try to address these issues, CFR has engaged in studies of the exposure-response of animals to a number of the primary toxic species, individually and in combination [23]. Species studied include carbon monoxide, carbon dioxide, hydrogen cyanide, reduced oxygen, and hydrogen chloride (being studied at SwRi with respect to both lethality and incapacteation on a grant). Simultaneously, Japanese researchers have been studying these and a few additional gases with incapacitation as an end point [24,25]. At this time, considerable data has been generated and 1 ts analysis has resulted in the development of some mathematical expressions based on empirical correlations to these data. While such empirical correlations will be valuable as an interim step, it is recognized that the final method must include kinetic uptake models which include the effect of activity on respiration rate, uptake, elimination, and metabolic changes in absorbed toxicants which impact on the eventual results of the exposure. 
Another portion of the exposure-response element is that of the evacuation process and the behavioral aspects of occupants during this process. In this area at CFR, Alvord has published an evacuation model for large buildings [26]. This model can be used to predict the period of time any occupant spends in any compartment and thus provides input necessary along with the concentration-time history provided by the transport model to obtain exposure-dose.

Working in conjunction with or to be included within the escape and rescue model is a decision/behavioral model under development by Levin. This will model certain aspects of typical human behavior in fire situations such as the response to initial, ambiguous cues concerning the fire and the tendency of males to investigate before taking escape actions. The model also includes such factors as the need to rescue infants and to assist the elderly or handicapped individuals.

\subsection{Fire.Protection Systems/HVAC}

The ability to model the operation of fire protection systems such as detectors and sprinklers or smoke control systems is an important factor in hazard analysis since it impacts on the notification aspect (and thus the point at which evacuation begins), and on the potential to control both the fire and the generation and spread of its products. In addition, HVAC systems can be a factor in mixing within a compartment and as a distribution path within large buildings. Thus, these systems need to be included in the overall hazard modeling. 


\subsubsection{Modeling Fire Protection Systems}

Currently, it is possible to predict accurately the operation of heatactivated devices (heat detectors and sprinklers) as a function of predicted conditions in the room of origin [27]. Estimates of the operating times of smoke detectors as a function of soot mass concentration or number concentration can be made with less accuracy for optical and ionization types, respectively [28].

Modeling the extinguishment process by sprinklers is not as advanced and may not be practically achieved for a few more years. Work on this is ongoing at NBS, Mission Research, Inc., and Factory Mutual Research Corporation in the U.S.

\subsubsection{HVAC Systems}

Currently, the transport models do not include forced ventilation either as a source of mixing or as a distribution path. For residential occupancles (small structures) this should not be a major drawback. For a larger structure, both factors need to be addressed and work on them is ongoing. We expect, within one year, to include a convection heater within a room to address the inter-layer mixing phenomena produced by it. Longer term research is needed before inclusion of HVAC systems as a transport path can be accomplished. 


\section{VALIDATION}

In order to be useful in a practical sense, models must be validated. That is, we must be able to establish the statistical accuracy of the predicted quantities. This requires much more than simply making direct comparisons with selected experimental results. Thus, CFR, in conjuction with the Center for Applied Mathematics (CAM) of the National Bureau of Standards has established a project to develop techniques to be used for this purpose. A summary report on validation was recently published by Davies [29], and a report on comparisons of FAST to a series of gas burner experiments in two and three room configurations will be published in the spring of 1986.

Interestingly, the ease of validating a model against test data is in many ways inversely proportional to the complexity of the modeling technique used. That is, comparisons are most direct for field models since they produce values of physical quantities at a specific point in space which corresponds directly to the location where the quantity was actually measured in an experiment. Zone models, on the other hand, produce what corresponds to a bulk average value within a layer. The average must be derived from experimental data by averaging some number of measured values within a layer which is continuously changing in volume. Since the measurements are taken at fixed points, one must determine according to an operational definition of layer interface location (which itself must be applied to the data) when they are within one layer or the other. Differences between measured and predicted values might be attributed to the poor quality or accuracy of the data, the paucity or low frequency of the data, the somewhat arbitrary definition of layer interface location, the poor performance of one or several of the 
predictive algorithms which make up the overall model, or a combination of these. This is not to say that model validation cannot be accomplished, but only that it represents a complex problem.

\section{MANAGING THE OUTPUT}

The output produced by models is in much the same form as data from large-scale fire experiments. That is, they give temperatures, flows, smoke densities, gas concentrations, radiant flux, etc. at fixed time intervals over the course of the simulation. The difference lies in the fact that fire experiments are expensive and time consuming to run, so their number is generally limited to a few, carefully selected scenarios.

Model runs, on the other hand, are easy to set up and inexpensive to produce, so the limitation with models is the ability to analyze and understand the large amount of data which is so readily available. Thus, it is critical that the models be provided with the capability of presenting their data in a way which is more easily understood, consistent with the purpose for which the model is being used.

Many applications will involve quantitative comparisons among numbers of model runs where parameters of interest have been varled. Here, general graphic techniques where $X-Y$ plots of predicted variables can be presented from one or more runs on a single graph would be useful. 
Such a capability is provided for FAST with a program called Fastplot (described in the appendix of ref. 12). For a more qualitative understanding of what would happen throughout an entire facility (especially a complex one) for a given set of conditions, this kind of presentation may not be appropriate. The large number of plots would lead to a confusing and unclear picture of the sequence of events.

To address this latter problem, we are developing a computer graphic technique which presents the information provided by the model in a two- or three-dimensional pictorial format along with graphical or tabular presentation of key quantities. This pictorial representation includes color coded hazard information which is also keyed to the data to show the relative contribution of a given parameter to the hazard condition present. In this way, key information is presented to the user in an easily understood manner similar to watching an experiment. Critical events can be noted during the graphical presentation and analyzed later by using the data graphics routines. With the evacuation sub-model, the graphics output can include occupants' progress displayed along with the environmental conditions to show either successful evacuation or the time, location, and condition which ultimately prevents escape. Mitigation strategies are then apparent to delay. the onset of the limiting condition sufficiently to allow successful evacuation.

\section{DATA SOURCES}

The biggest problem facing a potential user of any of the methods described above (from hand calculations through computer models) is obtaining the data required by the calculational technique as input. This is because 
most of these data involve properties which are either not measured or not reported in traditional property test methods.

Traditional test methods have been designed to produce pass-fail answers. Such yes/no results are the easiest for code authorities to enforce under the more traditional expert judgement codes, but they provide no detail on the quantitative performance of the material or product. Therefore, a new generation of test methods is under development which provide the needed property meas ur ements.

- Initially, these new generation test methods can serve a similar purpose under traditional code structure by providing quantitative rankings of material performance requiring that some ranking categories be developed. These ranking categories can be developed straightforwardly by testing trad1tionally acceptable products and using these as points of reference in the overall ranking process. This approach is similar to that which was used to develop the flame spread categories (A, B, C, and D) as applied to the Steiner Tunnel Test (ASTM E-84). Thus, the new test method can be used to replace the traditional test methods in the current code structure and at the same time begin to produce the property measurement data bank necessary for the predictive methods which will eventually lead to performance based codes. An initial report containing such data for use in models and calculations has been published recently by Gross [30].

The major drawback of this shift in test methods is that the traditional data base is not useful and we must start to build the new data base from scratch. This is, all materials in use must be re-tested. Thus, ingeneous 
ways to minimize the testing load must be found. One such scheme which relates to the quantification of combustion product release rates from materials, is the use of equivalence ratio correlations.

\subsection{Equivalence Ratio}

The idea behind equivalence ratio is quite simple. That is, that combustion is an oxidation reaction where the chemistry is controlled by the available oxygen. If, for example, a hydrocarbon fuel is burned under completely stoichiometric conditions (as in a premixed burner), the resulting products will be $\mathrm{CO}_{2}$ and $\mathrm{H}_{2} \mathrm{O}$ - all the carbon and hydrogen go to stable oxidized forms. If, however, stoichiometry is not maintained, products of incomplete combustion will be formed due to a lowered temperature of reaction if there is insufficient fuel or different chemistry if there is insufficient oxygen.

$A$ common application of this is the use of $\mathrm{CO} / \mathrm{CO}_{2}$ ratio as a measure of combustion efficiency in automobile exhaust or furnace effluent. In either case, a rising ratio indicates the need for adjustment of the air/fuel mixture in order to improve the combustion efficiency and reduce pollution.

In fire protection, we are most interested in diffusion flames which, by definition, contain regions of fuel-rich combustion. Within these regions, the excess fuel produced yields products of incomplete combustion which are also often the toxic species which we need to quantify. Thus, some means of predicting this chemistry would be valuable. If, in fact, the chemistry is only a function of the oxygen concentration at the reaction site (or more 
correctly how close it is to the stoichiometric value for the fuel), then we should see the yields of products of incomplete combustion collapse to a single curve when plotted against the local fuel/air ratio normalized to the stoichiometric value (defined as the equivalence ratio). This collapse to a single curve has been demonstrated by a number of researchers for a small range of fuels, including gases, liquids and solids, under fairly well controlled combustion conditions. Examples of Beyler's results for two fuels are shown in figs. 5 and 6.

This approach has been pursued by Beyler, Faeth, Tewarson, and Zukoski with some success. The general feeling is that it may work for some species $\left(\mathrm{CO}, \mathrm{CO}_{2}, \mathrm{H}_{2} \mathrm{O}, \mathrm{THC}\right)$ but not for others ( $\mathrm{HCl}, \mathrm{HCN}$, soot). We very much need to sort out which ones and why or why not. Another problem is that the effect is surely local within individual reaction sites but we must treat it as a global effect within the layers defined by a zone model. Thus, we must know something about the resultant errors. Finally, the effect relates to the fuel stoichiometry; so what happens with mixed or composite fuels where each has a different stoichiometric value?

Assuming that we can obtain answers to these questions, the benefit to our program would be enormous. Any fuels with similar chemical structure would be expected to have the same yields of major species. This could be verified experimentally in the cone by testing the material at three points: fully ventilated, fully vitiated, and a point on the slope of the curve. Such testing could be done in the modified cone with the enclosed combustion section by adjusting the $\mathrm{O}_{2}-\mathrm{N}_{2}$ ratio in the combustion a1r. The result is a greatly reduced number of cone tests needed to characterize a material. 
Tewarson's small-scale apparatus also has this capability and he has stated that he feels this is the best approach to supply modelers with the data they need to predict species concentrations.

The application of this approach in the models requires the prediction of oxygen concentration in the layers. This is extant in the Harvard Code and is being added to FAST V18. Both use yields to calculate species, so the equivalence ratio approach will fit right in.

\section{THE APPLICATION OF HAZARD ANALYSIS}

The potential uses for these techniques are as varied as the potential users. Initially, we feel that the primary uses will be in the areas of fire investigations and analysis of the contribution of material toxicity relative to other fire hazards. In the former, the models can be used to sort out the most likely scenario from several possible theories of origin and spread Indicated by the evidence. In the latter, the models show all of the relevant hazard considerations and their interrelationships in a way which cannot be analyzed by any other means. In both cases, the increase in litigations associated with fires will likely provide the motivation to invest in these new technologies.

As confidence in these techniques grows through validation and successful application in these areas, we hope that codes will begin to shift toward acceptance of compliance equivalency based on a calculated hazard analysis, and eventually to a performance base. Once this begins, the building design community will be able to begin using models to improve safety and reduce the 
cost of fire protection through design trade-offs and elimination of redundancy.

Since any evaluation of the impact of the combustion toxicity of materials and products requires a knowledge not only of the potency but also of the time of exposure and the resulting inhaled dose, these models represent the only scientifically defensible approach. This is particularly true for large structures where time scales for both transport processes and evacuation are long.

The technology to do all of the things discussed in this paper is available today and, with a dedicated effort, can be Implemented within a few years. The key to achieving this goal is cooperation among the research, regulatory, and manufacturing communities to support the effort financlally, and with the exchange of data necessary to make this all work.

\section{EXAMPLES}

The two following appendices contain reprints of papers which demonstrate how a quantitative hazard analysis might be used for two different purposes. In Appendix A, a hand-calculated analysis is used to examine the relative toxic hazard of a PTFE plenum cable in the context of a fire in a commerclal occupancy. In Appendix B, a model is used to evaluate the Impact of material property modifications in upholstered furniture relative to parameters beyond the control of a manufacturer in a residential occupancy. 


\section{REFERENCES}

1. Lawson, J.R. and Quintiere, J.G., Slide Rule Estimates of Fire Growth, NBSIR 85-3196, National Bureau of Standards, Gaithersburg, MD 20899, June 1985.

2. Nelson, H.E., "FORMULAS" - A Computerized Collection of Convenient Fire Safety Computations, in press.

3. Cooper, L.Y., A Mathematical Model for Estimating Ava1lable Safe Egress Time in Fires, Fire and Materials, Vol. 6, Nos. 3 and 4, 135-144, 1983.

4. Babrauskas, V., COMPF2 - A Program for Calculating Post-Flashover Fire Temperatures, NBS TN 991, National Bureau of Standards, Gaithersburg, MD, June 1979.

5. Mitler, H.E. and Emmons, H.W., Documentation for CFC V, The Fifth Harvard Computer Fire. Code NBS-GCR-81-344, National Bureau of Standards, Gaithersburg, MD, October 1981 .

6. Smith, E. and Satija, S., Release Rate Model for Developing Fires, presented at the 20th Joint ASME/AIC National Heat Transfer Conference, August 1981 .

7. Zukoski, E.E. and Kaboda, T., Two-Layer Modeling of Smoke Movement in Building Fires, Fire and Materials, 4, 17 (1980).

8. MacArthur, C.D., Dayton Aircraft Cabin Fire Mode1, Version 3, Volume I, Physical Description, Dayton Univ. Research Inst. Report No. UDRI-TR-81-159, June 1982 .

9. Smith, E.E., Computer based hazard assessment using heat release rate test data, Fire Safety Journal, Vol. 9, Nos. I and 2 (1985).

10. Tanaka, T., A Model of Multiroom Fire Spread, NBSIR 83-2718, National Bureau of Standards, Gaithersburg, MD, August 1983.

11. Gahm, J.B., Computer Fire Code VI, NBS-GCR-83-451, National Bureau of Standards, Gaithersburg, MD, December 1983.

12. Jones, W.W., A Model for the Transport of Fire, Smoke, and Toxic Gases (FAST), NBSIR 84-2934, National Bureau of Standards, Gaithersburg, MD, September 1984.

13. Babrauskas, V., Lawson, J.R., Walton, W..D. and Twilley, W.H., Upholstered Furniture Heat Release Rates Measured with a Furniture Calorimeter, NBSIR 82-2604, National Bureau of Standards, Gaithersburg, MD 20899 (1982).

14. Babrauskas, V., Development of the cone calorimeter - a bench scale heat release rate apparatus based on oxygen consumption, Fire and Materials, 8, 81-95 (1984). 
15. Dietenburger, M.A., Furniture Fire Model, NBS-GCR-84-480, National Bureau of Standards, Gaithersburg, MD, November 1984.

16. Tewarson, A., Seale Effects on Fire Properties of Materials, NBS-GCR-85-488, National Bureau of Standards, Gaithersburg, MD 20899, February 1985 .

17. Babrauskas, V. and Krasny, J., Fire Behavior of Upholstered Furniture, NBS Monograph 173, National Bureau of Standards, Gaithersburg, MD 20899, November 1985.

18. Krasny, J.F. and Babrauskas, V., Burning Behavior of Upholstered Furniture Mock-Ups, J. of Fire Sciences, Vol. 2, No. 3, 205-235, May/June 1984.

19. Babrauskas, V., Upholstered Furniture Heat Release Rates: Measurements and Estimation, J. of Fire Sciences, 1, 9-32, Jan/Feb 1983.

20. Babrauskas, V., Upholstered Furniture Room Fires-Measurements, Comparison with Furniture Calorimeter Data, and Flashover Predictions, J. of Fire Sciences, 2, 5-19, Jan/Feb 1984.

21. Hartzell, G.E., Priest, D.N., and Switzer, W.G., Mathematical Modeling of Toxicological Effects of Fire Gases, Proceedings of the First International Conference on Fire Safety Science, NBS, Gaithersburg, MD 20899.

22. Bukowski, R.W., Evaluation of Furniture Fire Hazard Using a Hazard Assessment Computer Model, Fire and Materials, in press.

23. Levin, B.C., Determination of the Toxicological Effects of Fire Gases, Alone and in Various Combinations, for use in Toxic Hazard Assessment Models, presented at the Third Canada-Japan-USA Trilateral Study Group Meeting on Toxicity, Ottawa, Canada, October 1984, to be published.

24. Sakuri, T., Incapacitation Test Using Several Pure Gases and Their Mixtures, presented at the Third Canada-Japan-USA Trilateral Study Group Meeting on Toxicity, Ottawa, Canada, October 1984, to be published.

25. Nishimarv, Y. and Tsuda, Y., Study of Physiological DIsorders in Rats Caused by Poisionous Gases, presented at the Third Canada-Japan-USA Trilateral Study Group Meeting on Toxicity, Ottawa, Canada, October 1984, to be published.

26. Alvord, D.M., The Fire Emergency Evacuation Simulation for Multifamily Buildings, NBS-GCR-84-483, National Bureau of Standards, Gaithersburg, MD, December 1984 .

27. Evans, D.D., Thermal Activation of Extinguishing Systems, NBSIR 83-2807, National Bureau of Standards, Galthersburg, MD, March 1984.

28. Mulholland, G. and Jones, W.W., private communication. 
29. Davies, A.D., Applied Model Validation, NBSIR 85-3154, National Bureau of Standards, Gaithersburg, MD, January 1985.

30. Gross, D., Data Sources for Parameters Used in Predictive Modeling of Fire Growth and Smoke Spread, NBSIR 85-3223, National Bureau of

Standards, Gaithersburg, MD 20899 (1985). 
Table 1. Single Compartment Models

Name

Harvard $\mathrm{V} \cdot \mathrm{X}^{1}$

Cal Tech

DACF IR

$\mathrm{OSU}^{2}$

ASET

COMPF2
Type

Time dependent room fire

Smoke filling

Aircraft, early time, state transition

Time dependent room fire, OSU apparatus

Smoke filling

Post-flashover temperatures

${ }^{\text {Multiple fuel items }}$

${ }^{2}$ Wa11 burning (primitive) 
Table 2. Multiple Compartment Models

$\left.\begin{array}{l}\text { Harvard VI } \\ \text { BRI }\end{array}\right\}$

FAST
Lower layer fixed at ambient conditions

Two layer with vent mixing and lower layer contamination 
Table 3. Material Property Data

\begin{tabular}{|c|c|c|c|c|c|c|c|}
\hline & \multirow[b]{2}{*}{ Material/Product } & \multirow[t]{2}{*}{$\begin{array}{c}\text { Heat } \\
\text { Release } \\
\text { (per unit } \\
\text { area) } \\
\mathcal{q}^{\prime \prime} \\
\left(\mathrm{kW} / \mathrm{m}^{2}\right)\end{array}$} & \multirow[t]{2}{*}{$\begin{array}{c}\text { Heats } \\
\text { of } \\
\text { Combustion } \\
\Delta \mathrm{H}_{\mathrm{c}} \\
(\mathrm{KJ} / \mathrm{g})\end{array}$} & \multirow{2}{*}{$\begin{array}{c}\text { Smoke } \\
\text { Yield } \\
Y_{S} \\
(g / g)\end{array}$} & \multirow{2}{*}{$\begin{array}{c}\text { Ignition } \\
\text { Temperature } \\
\mathrm{T}_{\text {ig }} \\
\left({ }^{\circ} \mathrm{C}\right)\end{array}$} & \multicolumn{2}{|c|}{$\begin{array}{l}\text { Toxicity } \\
\text { LC } 50 \\
(\mathrm{mg} / \mathrm{l})\end{array}$} \\
\hline & & & & & & $\mathrm{F}$ & NF \\
\hline $\begin{array}{l}\text { NBS } \\
\text { Toxicity } \\
\text { Test } \\
\text { Materials } \\
{[1,2,3] *}\end{array}$ & $\begin{array}{l}\text { ABS } \\
\text { Douglas Fir } \\
\text { Flexible PU Foam } \\
\text { Modacrylic Fabric } \\
\text { PTFE } \\
\text { PVC } \\
\text { Rigid Polystyrene } \\
\text { Red Oak } \\
\text { Rigid Polyurethane } \\
\text { Wool Fabric }\end{array}$ & $\begin{array}{r}460 \\
217 \\
500 \\
- \\
- \\
70 \\
720 \\
120 \\
221 \\
199\end{array}$ & $\begin{array}{l}35.3 \\
21.09 \\
24.64 \\
24.72 \\
5.0 \\
16.44 \\
39.7 \\
17.78 \\
40.84 \\
20.82\end{array}$ & $\begin{array}{l}0.21 \\
0.010 \\
0.02 \\
- \\
0 \\
0.091 \\
0.030 \\
0.013 \\
0.12 \\
-\end{array}$ & $\begin{array}{l}575 \\
465 \\
370 \\
725 \\
620 \\
600 \\
490 \\
480 \\
550 \\
650\end{array}$ & $\begin{array}{l}19.3 \\
39.8 \\
>40 \\
4.4 \\
.045 \\
17.3 \\
38.9 \\
56.8 \\
13.3 \\
28.2\end{array}$ & $\begin{array}{l}30.9 \\
22.8 \\
26.6 \\
5.3 \\
.045 \\
20.0 \\
>40 \\
30.3 \\
>40 \\
25.1\end{array}$ \\
\hline $\begin{array}{l}\text { Wire/Cable } \\
\text { Insulation } \\
{[4,5,6]}\end{array}$ & $\begin{array}{l}\text { PTFE } \\
\text { Silicone } \\
X P E / F R X P E \\
X P E / C \ell \cdot S \cdot P E \\
P E, P P / F R C \& \cdot S \cdot P E \\
X P E / N e O \\
P E / P V C\end{array}$ & $\begin{array}{l}43 \\
29 \\
22 \\
33 \\
36 \\
34 \\
36\end{array}$ & $\begin{array}{l}3.2 \\
25.0 \\
28.3 \\
13.9 \\
29.6 \\
10.3 \\
25.1\end{array}$ & $\begin{array}{l}0 \\
0 \\
0.22 \\
0.30 \\
0.15 \\
0.32 \\
0.21\end{array}$ & $\begin{array}{l}660 \\
573 \\
516 \\
600 \\
620 \\
607 \\
620\end{array}$ & $\begin{array}{l}1.1 \\
775 \\
46 \\
46 \\
46 \\
46 \\
27\end{array}$ & \\
\hline $\begin{array}{l}\text { Mattresses } \\
\text { (core/ } \\
\text { ticking) } \\
{[2,3,7]}\end{array}$ & $\begin{array}{l}\text { Polyurethane/PVC } \\
\text { Polyurethane/PVC } \\
\text { (Innerspring) } \\
\text { Cotton/PVC } \\
\quad \text { (Innerspring) } \\
\text { Latex/PVC } \\
\text { Polyurethane/Rayon } \\
\text { Cotton \& Polyester/ } \\
\text { Polyester } \\
\text { Cotton/Cotton } \\
\text { (Innerspring) } \\
\text { Neoprene/Cotton } \\
\text { Polyurethane/ } \\
\text { PVC \& Nylon }\end{array}$ & $\begin{array}{r}1300 \\
400 \\
\\
30 \\
1375 \\
800\end{array}$ & $\begin{array}{r}24.9 \\
24.8 \\
7.5 \\
28.0 \\
23.0\end{array}$ & $\begin{array}{l}0.10 \\
0.11 \\
0.05 \\
0.20 \\
0.02\end{array}$ & $\begin{array}{l}400 \\
400 \\
525 \\
- \\
400\end{array}$ & $\begin{array}{c}37.7 \\
32.1 \\
42 \\
-- \\
41\end{array}$ & \\
\hline $\begin{array}{l}\text { Misc. } \\
\text { Materials } \\
{[5,6]}\end{array}$ & $\begin{array}{l}\text { Cotton } \\
\text { Vinyl Floor Tiles } \\
\text { Nylon Carpet }\end{array}$ & $\begin{array}{r}20 \\
16 \\
350\end{array}$ & $\begin{array}{l}18 \\
18 \\
29\end{array}$ & $\begin{array}{l}0.005 \\
0.2 \\
0.1\end{array}$ & $\begin{array}{l}525 \\
470 \\
475\end{array}$ & $\begin{array}{c}47 \\
83 \\
21.6\end{array}$ & \\
\hline
\end{tabular}

*Numbers in brackets refer to the sources of the data presented in each section from the list on the following page. 
1. Levin, B.C. et al., "Further Development of a Test Method for the Assessment of the Acute Inhalation Toxicity of Combustion Products", NBSIR 82-2532, NBS, Gaithersburg, MD 20899 (1982).

2. "Materials Bank Compendium of Fire Property Data", Products Research Committee, Feb. 1980.

3. McKinnon, G., Editor, "Fire Protection Handbook - 15th Edition, NFPA, Quincy, MA 02269, Section 4, Chapter 12.

4. Tewarson, A., "Categorization of Cable Flammability, Part 1: Laboratory Evaluation of Cable Flammability Parameters", EPRI Report NP-1200, Part 1, Electric Power Research Institute, Palo Alto, CA 94304, Oct. 1979.

5. Matijak-Schaper, M. et al., "Toxicity of Thermal Decomposition Products from Commonly Used Synthetic Polymers", Fire Science and Technology, Vol. 1, No. 1, Oct. 1982.

6. Levin, B.C., unpublished data.

7. Babrauskas, V., "Combustion of Mattresses Exposed to Flaming Ignition Sources, Part II. Bench-Scale Tests and Recommended Standard Test", NBSIR 80-2186, NBS, Gaithersburg, MD 20899, Feb. 1981. 
Table 4. Thermal Properties of Room Lining Materialsa

Aluminum (pure)

Concrete

Asbestos-cement

board (heavy)

Brick

Brick/concrete block

Gypsum board

Plasterboard

Plywood

Chipboard

Aerated concrete

Cement-asbestos board

Calcium silicate board

Fibre insulation board

Alumina silicate block

Glass fibre insulation

Expanded polystyrene

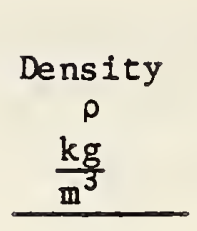

2710

2400

2100

2600

1900

960

950

540

800

500

658

700

240

260

60

20
Specific Heat

c.

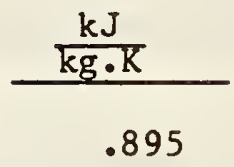

.75

1.0

0.8

.84

$1 \cdot 1$

.84

2.5

1.25

.96

1.06

1.12

1.25

$\langle 1\rangle$

$$
.8
$$

1.5
Thermal

Conductivity

$\mathrm{k} \times 10^{3}$

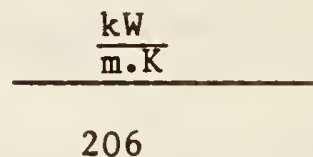

$k p c$

500

2.88

1.1

2.31

0.8

1.66

.73 .

1.17

.17

0.180

.16

.0 .127

.12

0.162

.15

0.150

.26

0.1248

.14

0.0976

$.11-.14$

0.0862

0.53

0.0159

.14

0.0464

.037

$1.78 \times 10^{-3}$

.034

$1.02 \times 10^{-3}$

aFrom reference [39] 


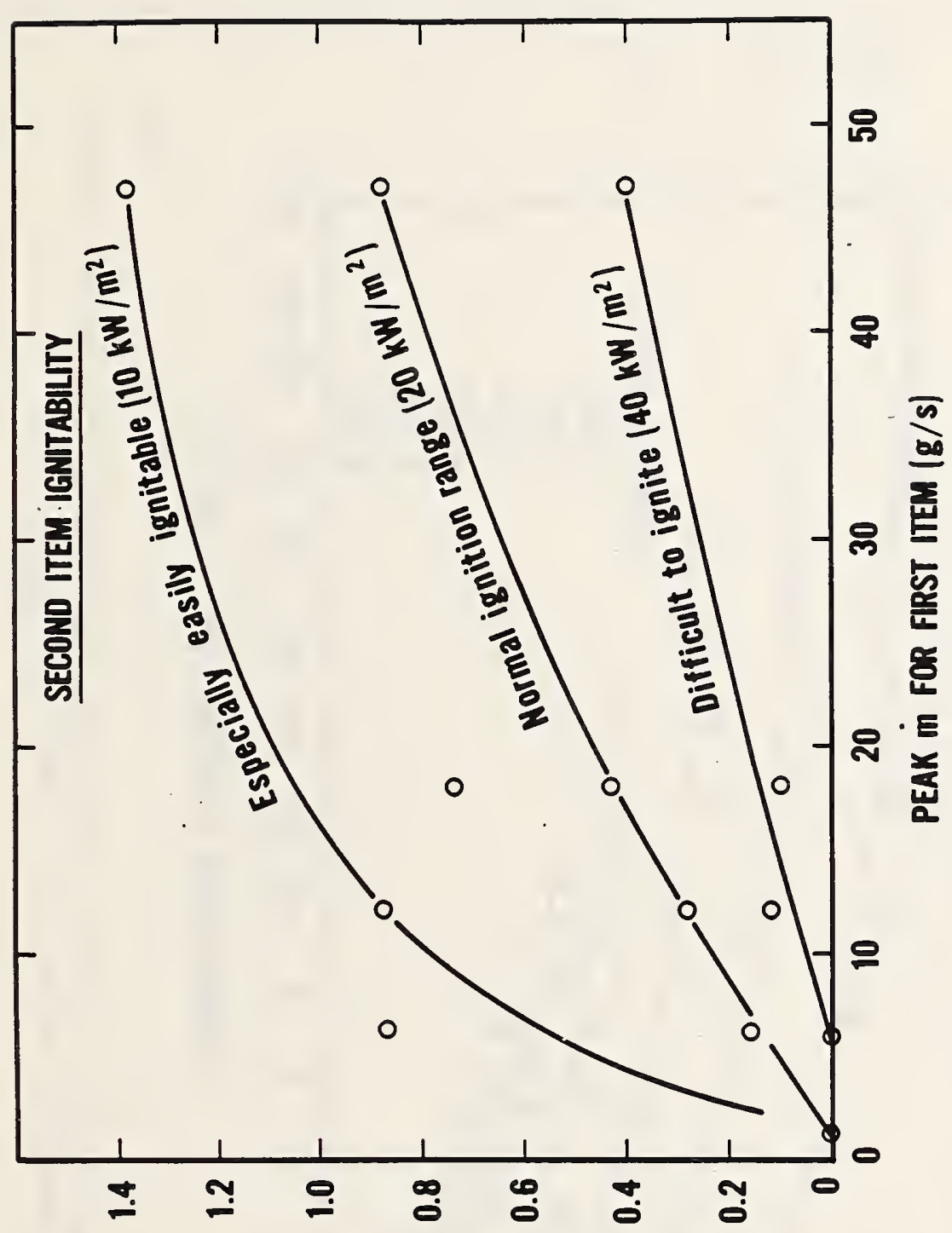

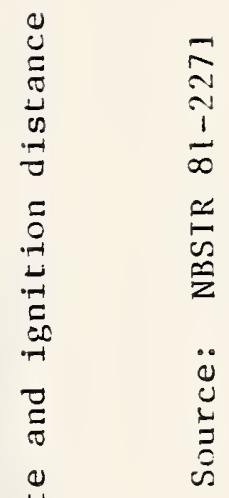

(ய) 3อNY1SIO NOIIN9I 


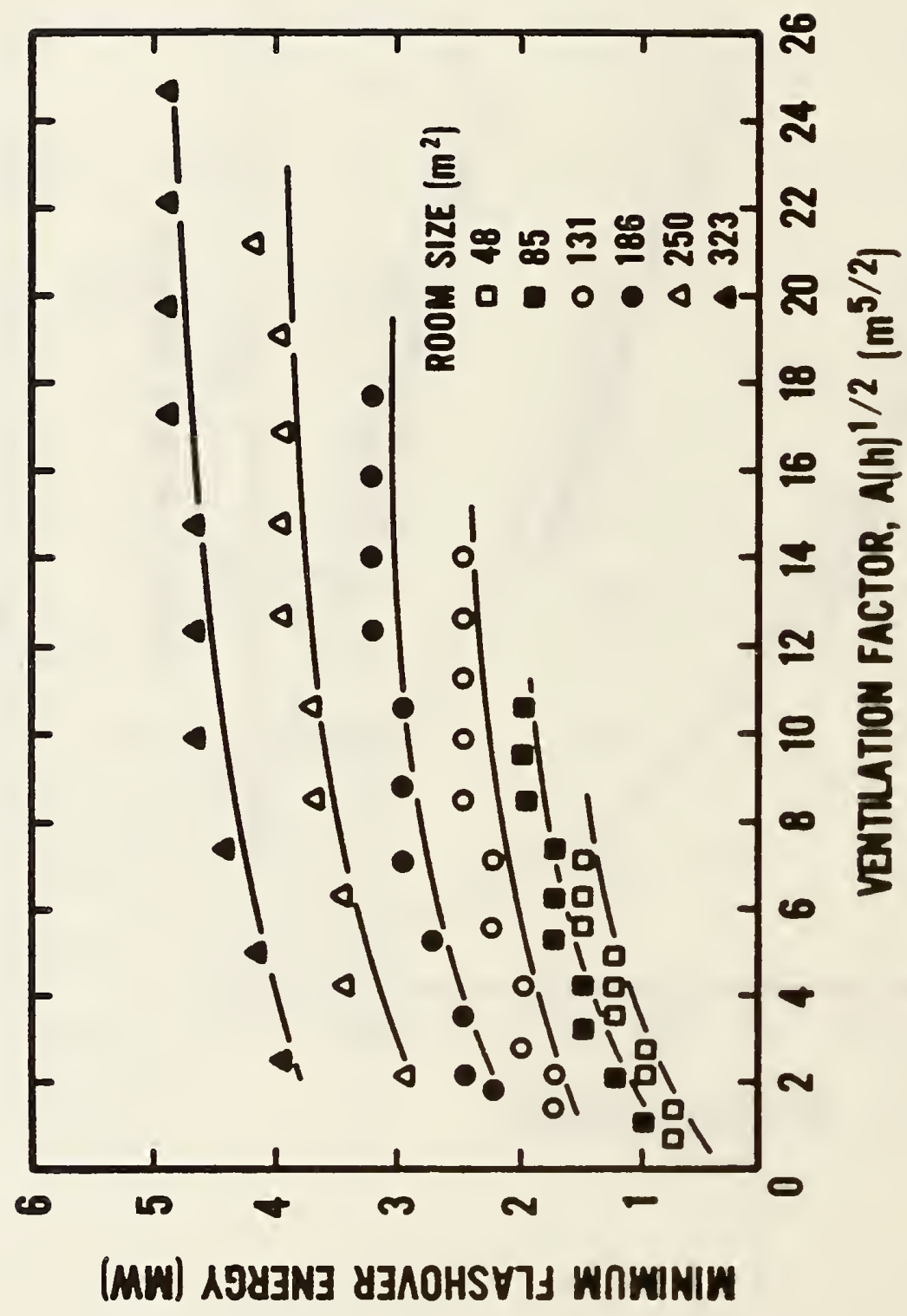

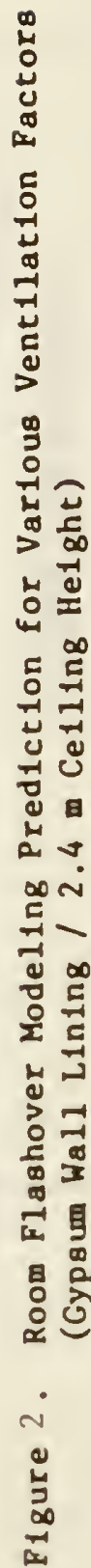




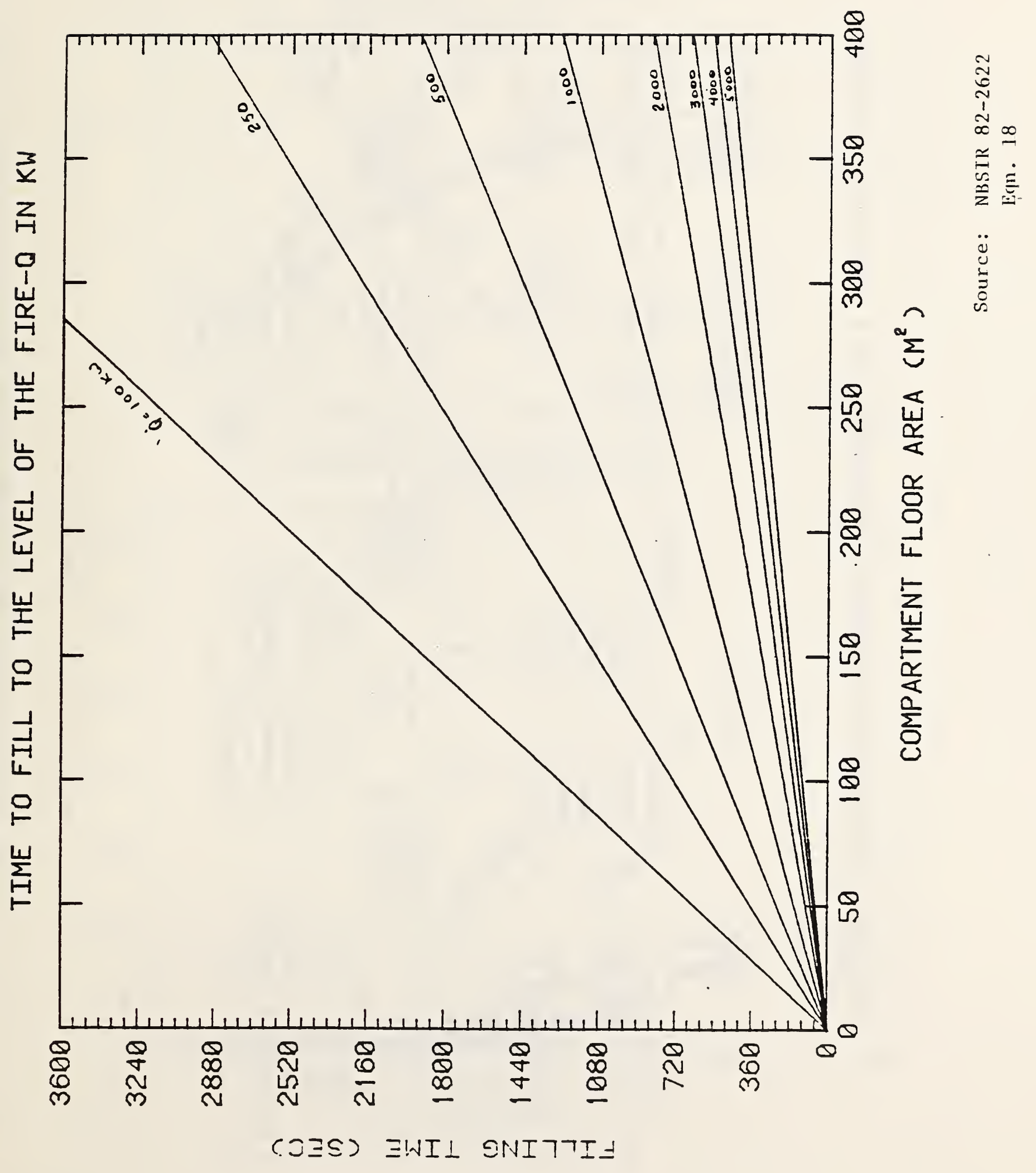




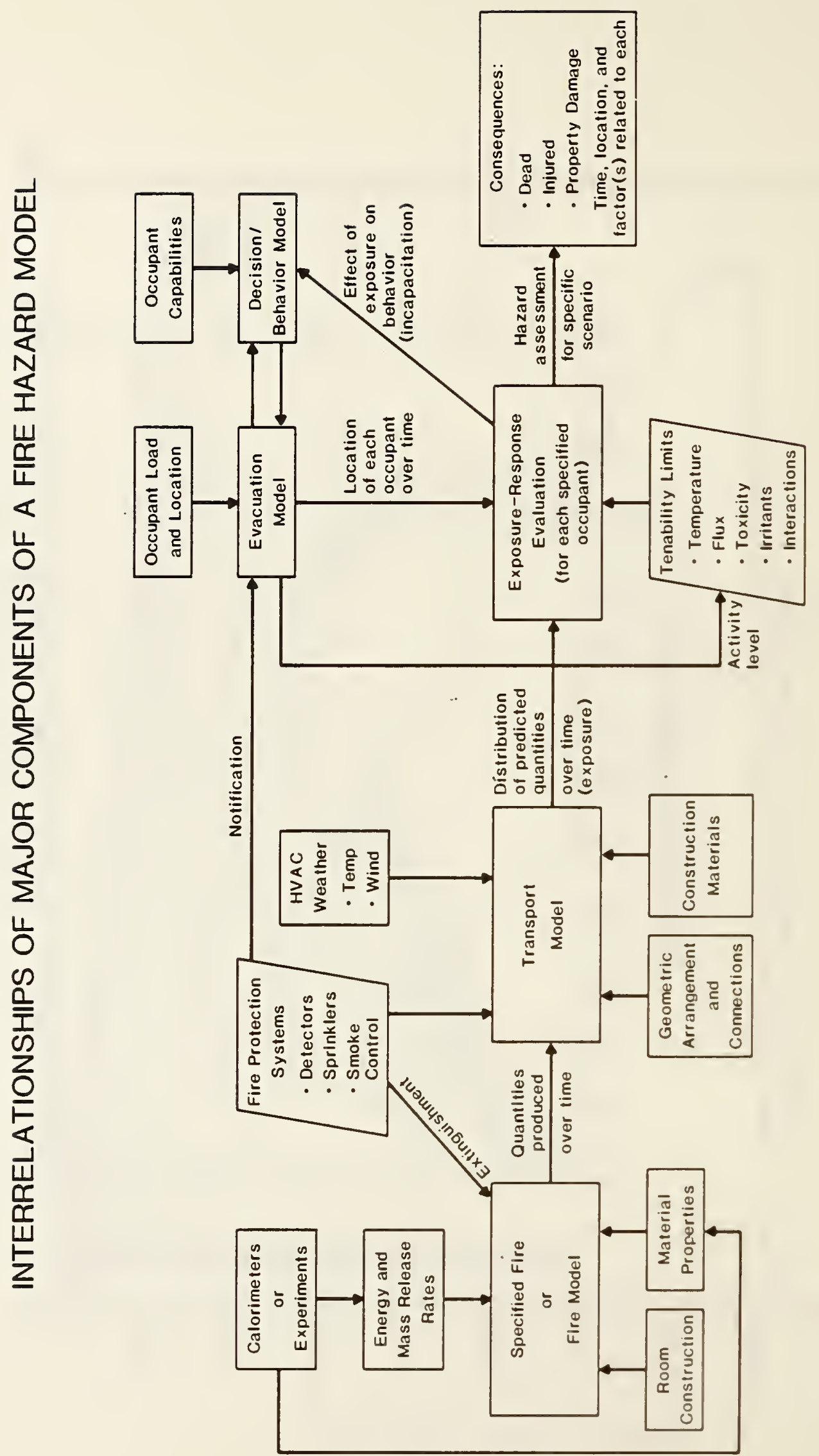




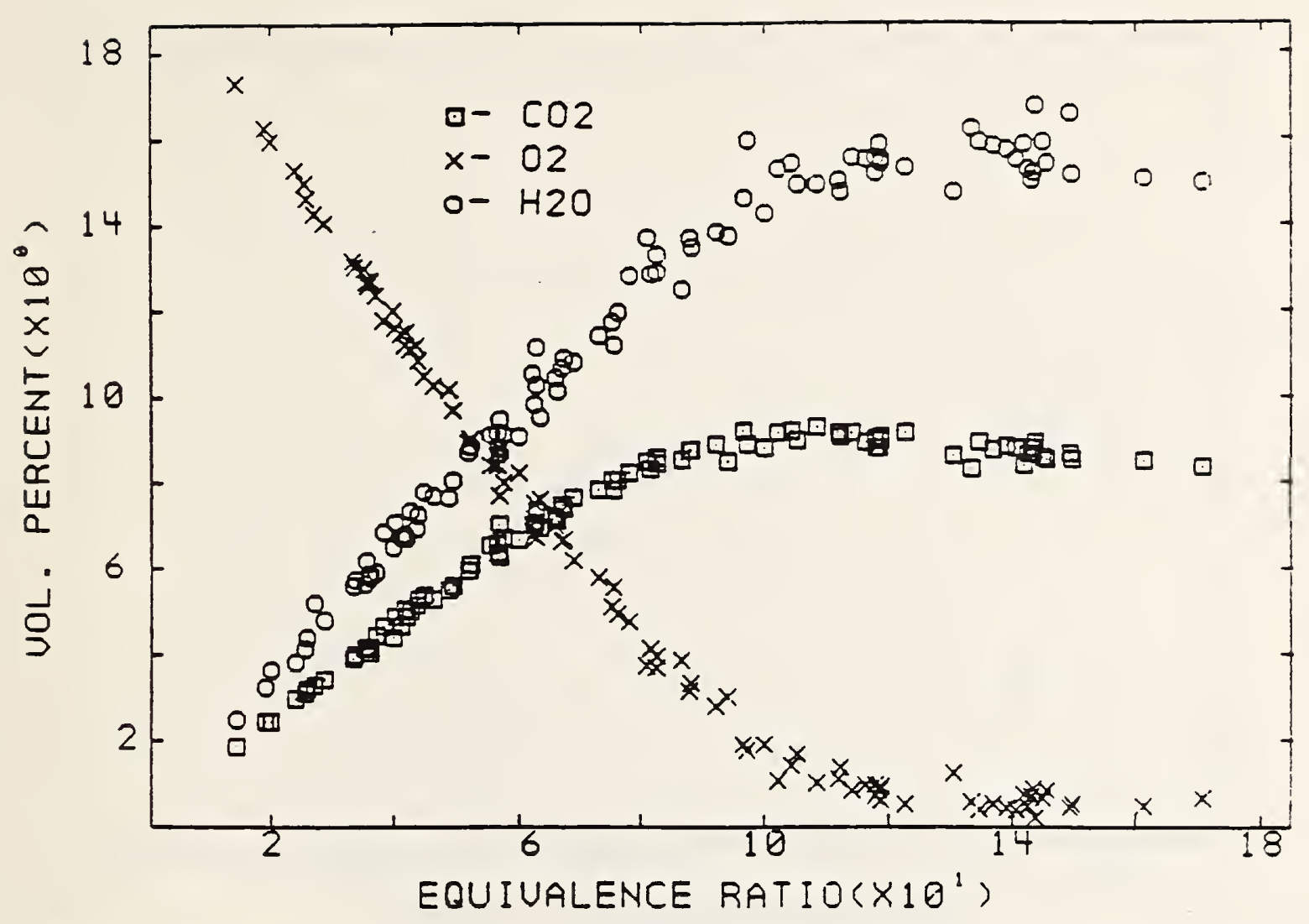

Fig. 4-1

PROPANE

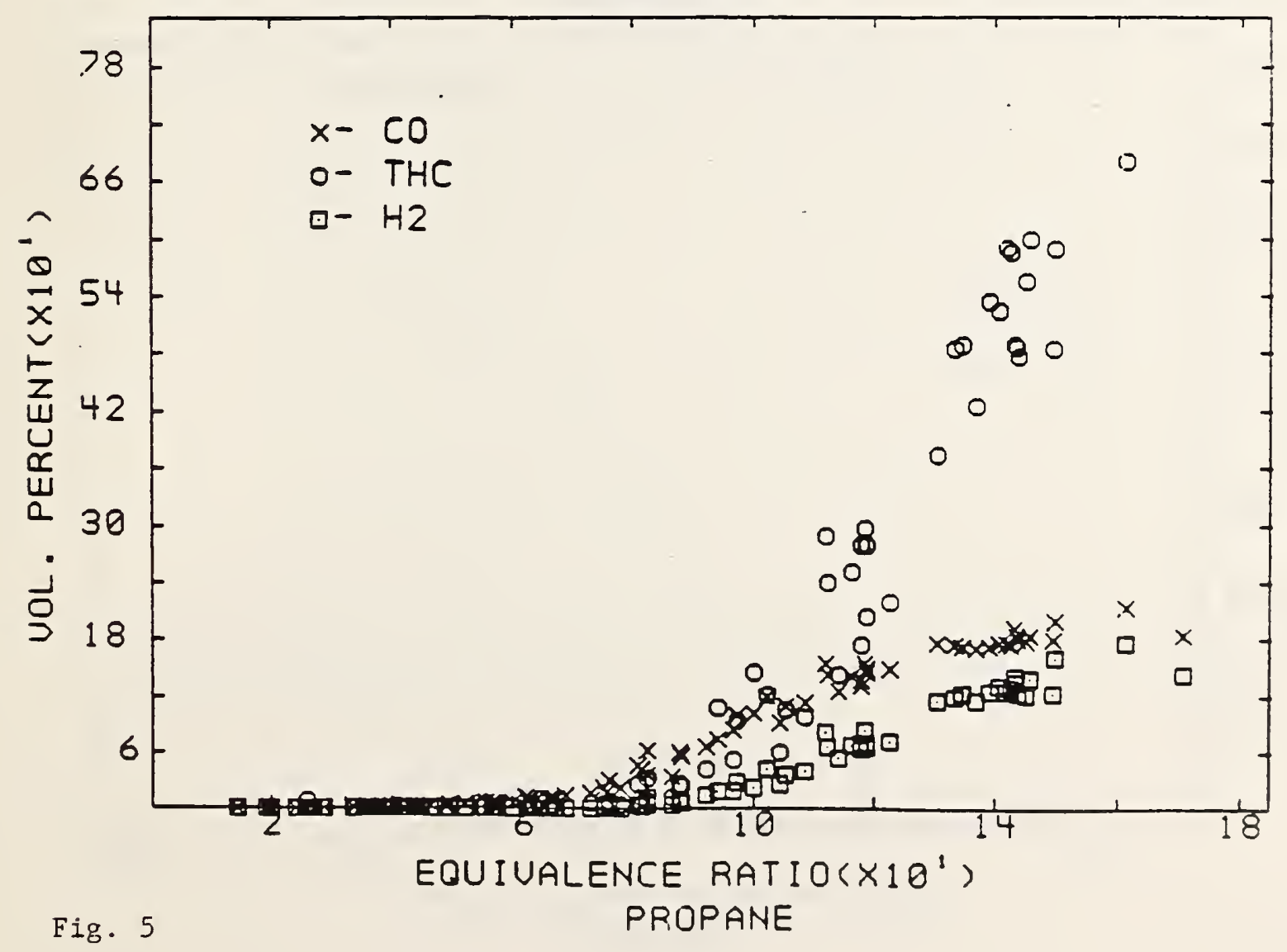




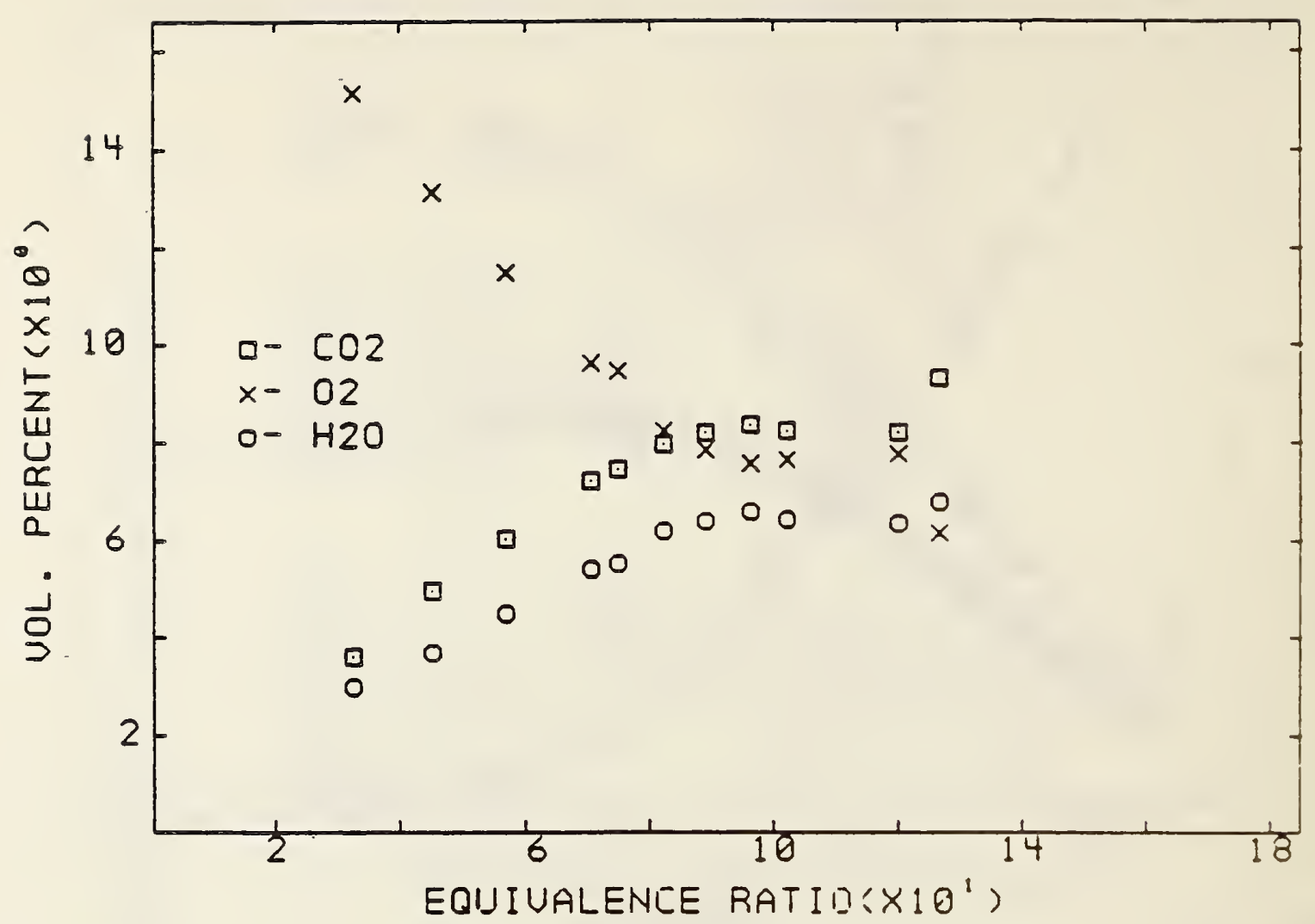

Fig. 4-39 TOLUENE

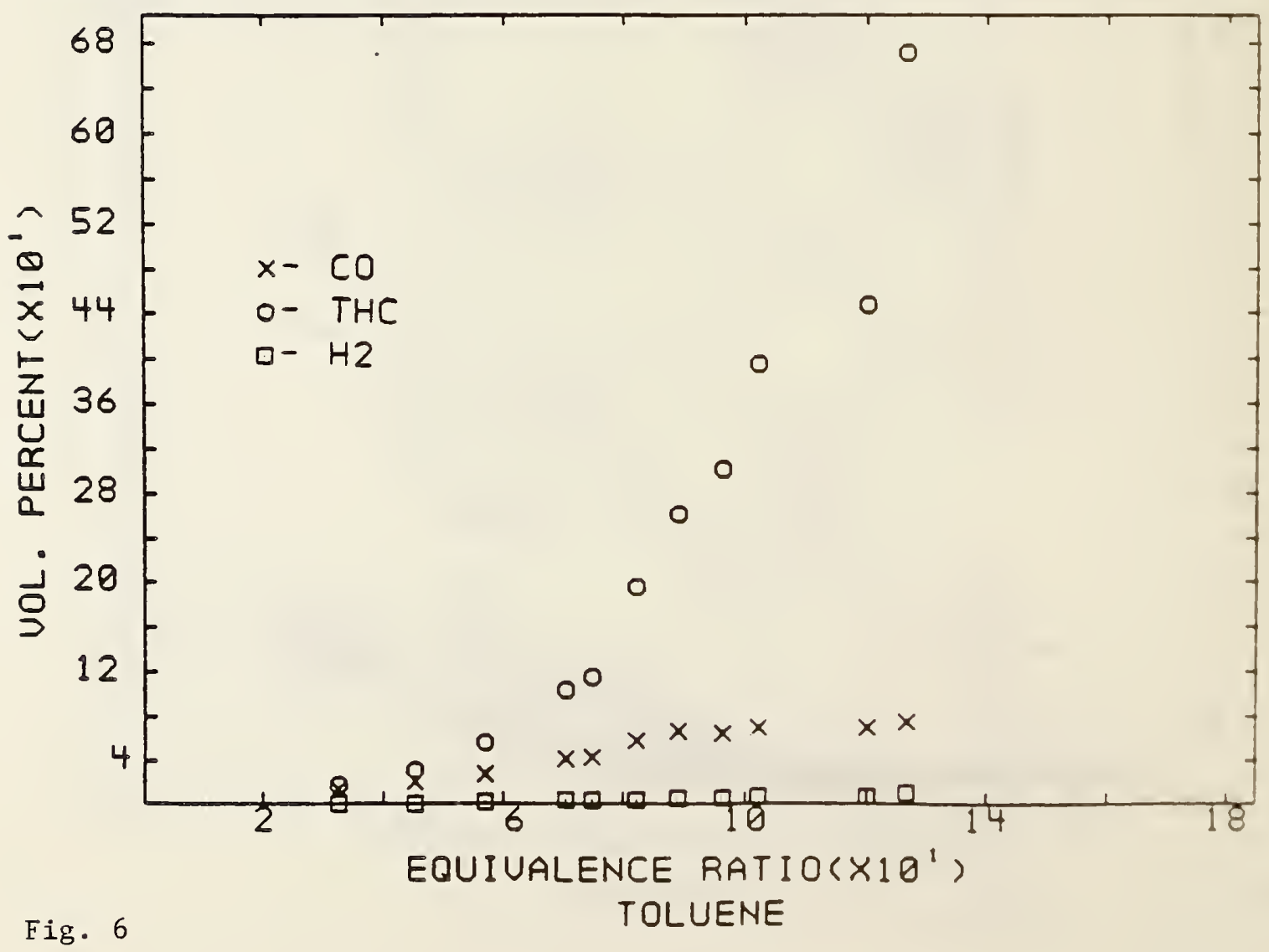


APPENDIX A

TOXIC HAZARD EVALUATION OF PLENUM CABLES 


\title{
Toxic Hazard Evaluation of Plenum Cables
}

\author{
RICHARD W. BUKOWSKI, P.E. \\ Center for Fire Research \\ National Bureau of Standards
}

(Paper submitted October 1984, accepted May 1985)

\begin{abstract}
Code provisions covering the installation of low voltage cables in plenum spaces above suspended ceilings used for environmental air are reviewed. A calculation procedure which could be used to estimate the potential toxicity of the decomposition products from these cables relative to the toxicity of the compartment fire necessary to decompose the cable insulation is presented. These estimates are used in a four-step procedure for estimating Smoke Toxicity Hazard proposed by the NFPA Toxicity Advisory Committee which is described. Example calculations for some typical cases and a discussion of their limitations are included.
\end{abstract}

\section{INTRODUCTION}

T MAY OF 1984 the Toxicity Advisory Committee of the National Fire Protection Association (NFPA) presented a procedure for providing "order of magnitude estimates" of the toxic hazard of smoke for specified situations." This procedure was suggested for potential use by the technical committees of NFPA in helping them assess the relative contribution of toxic products to the overall hazards of fire in evaluating standards proposals. This paper presents an example calculation intended to illustrate the use of this procedure. In general, one calculation by itself will not be sufficient for resolving all possible concerns, even this particular case. Rather one should expect that a number of such calculations be performed for the ranges of key parameters the technical committee members believe are likely. This should lead either to resolution of the concerns or identification

Reference: Richard W. Bukowski, "Toxic Hazard Evaluation of Plenum Cables," Fire Technology, Vol. 21, No. 4, November 1985, p. 252.

Key Words: Toxic hazard, cable, plenum, fluorinated-thylene-propylene (FEP), polytetrafluoroethylene (PTFE), floor-ceiling assembly, thermal decomposition, thermal conductivity. heat transfer.

This paper is a contribution of the National Bureau of Standards and is not subject to copyright.

252 
of those specific cases for which more detailed analyses, data or tests may be desired.

The widespread growth in the use of computers and other automatic data transmission equipment in commercial occupancies has resulted in a significant increase in the quantity of low voltage signal and communication cabling in such buildings. Since suspended ceiling systems are quite common in these structures, the most convenient and practical place to route the cables is through this above-ceiling space which is also often used for environmental air. Current building and fire codes commonly require such cables to be "listed as having adequate fire resistant and low smoke producing characteristics." 2 The most common cable insulation type having these characteristics is a fluorocarbon type material such as FEP or PTFE (fluorinated-ethylene-propylene or polytetrafluoroethylene).

Recently, combustion toxicity testing of PTFE has indicated an apparent toxicity three orders of magnitude more toxic than wood when decomposed under certain laboratory conditions. ${ }^{3}$ This has caused some concern about the possible toxic hazard of PTFE cables within plenum spaces. The following represents an initial look at the problem and an attempt to provide "order of magnitude estimates" of what might be expected when a fire occurs in a compartment below a plenum space containing PTFE cables using the procedures suggested by the National Fire Protection Association Toxicity Advisory Committee."

\section{EXISTING CODE REQUIREMENTS}

Article 300 of the National Electrical Code (NFPA 70) contains requirements for electrical power wiring in ducts, plenums, and other air handling spaces. Section 300-22 (c) allows only metal covered types of cabling in spaces, such as suspended ceiling spaces, used to transport environmental air that are not specifically manufactured as ducts or plenums. But this pertains only to class 1 wiring systems. Articles 725 (remote control, signaling, and power limited circuits); 760 (fire protective signaling systems); 770 (optical fiber cables); 800 (communication circuits), and 820 (community antenna television), all specifically allow class 2 and class 3 circuits to be run in unenclosed cabling within ducts and plenums and other spaces used for environmental air provided such cables are listed as having adequate fire resistant and low smoke producing characteristics.

NFPA 90A contains a similar requirement for such unprotected cables to be fire resistant and low smoke producing. If the floor-ceiling assembly is not fire rated, some additional requirements are imposed to delay possible collapse of the suspended ceiling system.

Of the model building codes, the Basic Building Code (1981) and Standard Building Code (1982) require conformance with the National Electrical Code. The Uniform Building Code (1982) appears to allow only factory assembled multiconductor cable which is specifically listed for such use and only when the building is protected by an automatic sprinkler system or the 
plenum space is protected by a smoke detection system which, upon activation of either system, will cause the air moving equipment to shut down.

While at least 15 laboratory procedures for testing toxicity of combus. tion products were reported in the literature by $1976,{ }^{4}$ the relevance of laboratory toxicity data to practical firesafety measures has been controversial over the past decade. ${ }^{5.6}$ Specific code requirements have not been established nor is such a course universally endorsed within the fire science community. Although a total consensus has yet to be achieved, one major direction both in the United States ${ }^{1}$ and internationally ${ }^{7}$ has been to view laboratory toxicity tests as potential sources of input data for hazard analysis applied to specific situations. This avoids the obvious shortcomings of attempting to classify materials as acceptable or unacceptable without reference to the circumstances of use.

\section{PROCEDURE FOR ESTIMATING TOXIC HAZARD FOR A SPECIFIED SITUATION}

The NFPA Toxicity Advisory Committee proposed a four step procedure for estimating the incremental change in toxic hazard represented by the use of specific materials in a given context. ${ }^{1}$ These steps are:

1. Define the context of use of the proposed material, product, or procedure. This includes the occupancy, its design, occupants and their capabilities, other materials, products, systems involved, etc.

2. Identify the scenarios of concern regarding the use of the proposed material.

3. Develop quantitative estimates of the magnitude of the hazards to life for each of these scenarios; the principal hazards being thermal and toxic smoke exposures.

4. Evaluate the consequences in terms of total and incremental losses from addition of the proposed material or product, or its substitution for the traditional alternative.

\section{Context OF USE}

For the present case, the material in question is low voltage (class 2 and 3) PTFE insulated cables located within the void space between a suspended ceiling and the floor slab above where this space is used for environmental air (either supply or return). Where the space is not used for environmental air, no specific restrictions on wire types (other than general wire installation requirements applicable to any other areas of a building) are imposed by the codes. Toxicity testing of other types of plenum cable insulation has not revealed any unusual toxicity when compared with other (limited) combustible materials which are allowed in such spaces.

The occupancies in which such materials are present include primarily business and mercantile, but may also inclucie educational or assembly. Oc- 


\section{Plenum Cables}

cupants are assumed to be mobile and alert when present during hours of operation. Principal combustibles are assumed to be building contents furniture and furnishings.

\section{SCENARIO(s) OF CONCERN}

The scenario of interest involves PTFE insulated cables run in a plenum space used for environmental air (typically return air) above a compartment in which a fire occurs. The proposed material, PTFE insulated cables, is not likely to self ignite from electrical failure nor be ignited or heated by fire from other combustibles in the space above the suspended ceiling. Rather, the scenarios of concern involve burning combustibles below the suspended ceiling which lead to heating of the cables. Such combustibles may include office furniture, papers, or furnishings or merchandise. The fires of concern may include, for example, a large item of furniture with or without flashover of the compartment. The fires of concern range from small exposures affecting only a small portion of the cabling to larger plumes which lead to elevated temperatures of the entire ceiling and even flashover of the com. partment. The potential toxic hazard would come from the movement of the cable insulation decomposition products from the plenum space to some occupied area, where it would add to the toxic hazard of smoke from the compartment fire.

\section{Estimate Hazards to Life}

\section{Approach}

The relative hazard to life from smoke toxicity is estimated by first calculating the likely smoke exposure produced by the materials involved in the scenario of concern and then by considering the response of occupants to the exposure - both with and without the proposed material involved. The smoke exposure resulting from the scenario of concern is calculated as follows:

$$
\text { Smoke Exposure }=(\text { Smoke Concentration }) \times(\text { time exposed })
$$

where

$$
\text { Smoke Concentration }=\frac{\text { mass burned }}{\text { volume filled }}
$$

and

$$
\text { mass burned }=\text { burning rate } \times \text { time. }
$$

\section{Estimate mass loss}

For this case we need to estimate both the mass of PTFE likely to be involved and that of the materials which produce the heat to decompose the PTFE. 
Since suspended ceilings which form a part of fire rated floor-ceiling assemblies and many nonrated assemblies are made of noncombustible thermal insulating materials, they provide a significant barrier to the transmission of heat to the space above. Thus, the first question which must be answered is how big a fire in the compartment below is needed to release sufficient energy to produce temperatures in excess of the thermal decomposition temperature of the wire insulation in the plenum space. Since the thermal decomposition temperature of PTFE is known we can apply simple, steady state heat transfer calculations to estimate the size of fire in the compartment below necessary to decompose it. The important parameters of this problem are illustrated in Figure 1. Note that a more rigorous transient heat transfer analysis could be undertaken using computer fire modeling techniques if warranted.

This figure shows a compartment with a suspended ceiling system. plenum space, and structural slab. The compartment has a vent (doorway) to an adjacent space and a fire releasing energy $\left(\dot{Q}_{f}\right)$ at a constant rate which forms a hot upper gas layer at an average temperature of $T_{U L}$. Temperatures of interest include the lower and upper surface temperatures on the ceiling tile, average plenum space temperature, and surface temperatures on the lower and upper side of the structural slab (labeled $T_{1}$ through $T_{3}$, respec-

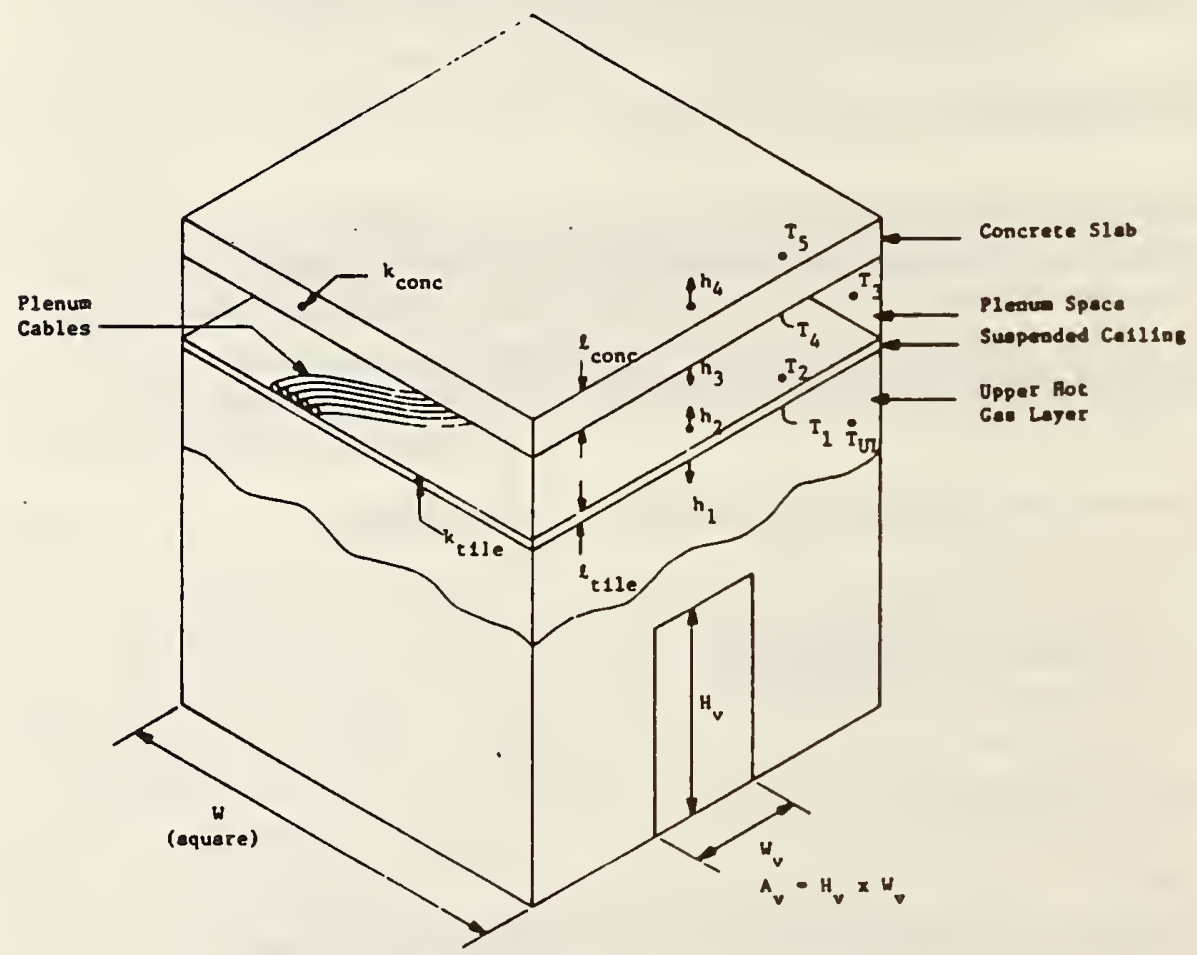

Figure 1. Compartment diagram. 


\section{Plenum Cables}

tively). The compartment vent (doorway) has an area of $A_{v}$ and a height of $H_{v}$. The plenum cabling of interest is assumed to be in physical and thermal contact with the upper surface of the ceiling tile.

For simplicity in illustrating the calculation, radiative heat transfer is neglected and the air flow is considered static (no forced convection). Inclusion of radiation would add $\mathrm{T}^{4}$ terms to the equations, greatly increasing the complexity of the solution. The resulting steady state conduction and convection equations for the system are given below:

$$
\text { heat transfer per unit area } \cong \dot{q}^{\prime \prime} ;\left(k W / m^{2}-\text { sec }\right)
$$

for conductive heat transfer through a material

$$
\dot{\mathrm{q}}^{\prime \prime}=\mathrm{k} \Delta \mathrm{T} / \ell
$$

where $\mathrm{k}=$ thermal conductivity, $\left(\mathrm{kW} / \mathrm{m}-{ }^{\circ} \mathrm{K}\right)$

$\Delta \mathrm{T}=$ temperature differential across it $\left({ }^{\circ} \mathrm{C}\right)$, and

$\ell=$ the thickness of the material (m).

For convective heat transfer

$$
\dot{\mathrm{q}}^{\prime \prime}=\mathrm{h} \Delta \mathrm{T} \text {. }
$$

where $h=$ convective heat transfer coefficient.

For steady state conditions, i.e. $\dot{\mathrm{q}}^{\prime \prime}$ is a constant, starting from the upper layer of hot gases created by the fire in the compartment and working up towards ambient temperature, $\mathrm{T}_{a}$, above the concrete floor/ceiling, we can apply Equations 2 and 3 using the definitions on Figure 1 as follows:

1. heat transfer from the fire through the upper layer (convective)

$$
\dot{\mathrm{q}}^{\prime \prime}=\mathrm{h}_{1}\left(\mathrm{~T}_{U L}-\mathrm{T}_{1}\right)
$$

2. heat transfer through the suspended ceiling (conductive)

$$
\dot{\mathbf{q}}^{\prime \prime}=\mathbf{k}_{\text {tire }}\left(\mathrm{T}_{1}-\mathrm{T}_{2}\right) / \ell_{\text {tile }}
$$

3. heat transfer from the suspended ceiling (convective)

$$
\dot{\mathrm{q}}^{\prime \prime}=\mathrm{h}_{2}\left(\mathrm{~T}_{2}-\mathrm{T}_{3}\right)
$$

4. heat transfer to the concrete (convective)

$$
\dot{\mathrm{q}}^{\prime \prime}=\mathrm{h}_{3}\left(\mathrm{~T}_{3}-\mathrm{T}_{4}\right)
$$


5. heat transfer through the concrete (conductive)

$$
\dot{\mathrm{q}}^{\prime \prime}=\mathrm{k}_{\text {conc }}\left(\mathrm{T}_{4}-\mathrm{T}_{5}\right) / \ell_{\text {conc }}
$$

6. heat transfer to air above concrete (convective)

$$
\dot{\mathrm{q}}^{\prime \prime}=\mathrm{h}_{4}\left(\mathrm{~T}_{\mathrm{s}}-\mathrm{T}_{a}\right)
$$

The thermal decomposition temperature of PTFE is cited in the literature as approximately $500^{\circ} \mathrm{C}\left(932^{\circ} \mathrm{F}\right) .^{8}$ Since the plenum cabling is assumed to be in thermal contact with the upper surface of the ceiling tile, we will then define the critical value of temperature $\mathrm{T}_{2}$ as $500^{\circ} \mathrm{C}$. This temperature represents a hazard threshold, since below it the material does not decompose and therefore does not contribute to the toxic threat of the fire.

Substituting the data in Table 1 we obtain for Equations 4-9,

$$
\begin{aligned}
\dot{\mathrm{q}}^{\prime \prime} & =10^{-2}\left(\mathrm{~T}_{v 2}-\mathrm{T}_{1}\right)=0.16 \times 10^{-3}\left(\mathrm{~T}_{1}-500\right) \frac{39.37}{1} \\
& =10^{-2}\left(500-\mathrm{T}_{3}\right)=10^{-2}\left(\mathrm{~T}_{3}-\mathrm{T}_{4}\right) \\
& =1.6 \times 10^{-3}\left(\mathrm{~T}_{4}-\mathrm{T}_{5}\right) \frac{39.37}{2}=10^{-2}\left(\mathrm{~T}_{5}-21\right)
\end{aligned}
$$

Simplifying

$$
\begin{aligned}
& \mathrm{T}_{5}=.7 \mathrm{~T}_{4}+6.25 \\
& \mathrm{~T}_{4}=.58 \mathrm{~T}_{3}+8.63 \\
& \mathrm{~T}_{3}=358.2^{\circ} \mathrm{C}\left(676.76^{\circ} \mathrm{F}\right) \\
& \mathrm{T}_{4}=216.4^{\circ} \mathrm{C}\left(421.52^{\circ} \mathrm{F}\right) \\
& \mathrm{T}_{5}=157.7^{\circ} \mathrm{C}
\end{aligned}
$$

and

$$
\dot{\mathrm{q}}^{\prime \prime}=1.42 \mathrm{~kW} / \mathrm{m}^{2}
$$

The steady state heat flux through the system is $\dot{\mathrm{q}}^{n}=1.42 \mathrm{~kW} / \mathrm{m}^{2}$ regardless of the suspended ceiling material selected since $T_{2}$ is assumed fixed at a given temperature.

From these values, we can derive simple expressions for $T$, and the upper layer temperature necessary to produce these temperatures in terms of the thermal conductivity $\left(k_{1}\right)$ and thickness $(\ell)$ of an arbitrary suspended tile material of interest. These expressions are given below:

$$
\begin{aligned}
& \mathrm{T}_{1}\left({ }^{\circ} \mathrm{C}\right)=500+\frac{1.42 \ell}{\mathrm{k}_{1}} \\
& \mathrm{~T}_{U L}\left({ }^{\circ} \mathrm{C}\right)=\mathrm{T}_{1}+142
\end{aligned}
$$


TABle 1. Assumed Data

1. $\mathrm{T}_{2}=500^{\circ} \mathrm{C}\left(932^{\circ} \mathrm{F}\right)$ thermal decomposition temperature of PTFE

2. Suspended Ceiling:

$$
\begin{aligned}
& \mathbf{k}_{\text {ute }}=0.16 \times 10^{-3} \mathrm{~kW} / \mathrm{m}-{ }^{\circ} \mathrm{K} \\
& \varrho_{\text {ete }}=385 \mathrm{~kg} / \mathrm{m}^{3} \\
& \ell_{\text {1.1e }}=2.54 \times 10^{-2} \mathrm{~m}(1 \mathrm{in} .) \\
& \mathrm{C}_{p}=1.06 \mathrm{~kJ} / \mathrm{kg}-{ }^{\circ} \mathrm{K}
\end{aligned}
$$

3. Concrete Slab:

$$
\begin{aligned}
& \mathbf{k}_{\text {conc }}=1.6 \times 10^{-3} \mathrm{~kW} / \mathrm{m}-{ }^{\circ} \mathrm{K} \\
& \ell_{\text {conc }}=5 \times 10^{-2} \mathrm{~m}(2 \mathrm{in} .)
\end{aligned}
$$

4. Convective heat transfer coefficients:

$$
h_{1}=h_{2}=h_{3}=h_{4}=10^{-2} \mathrm{~kW} / \mathrm{m}^{2}-{ }^{\circ} \mathrm{K}
$$

5. Ambient air temperature

$$
\mathrm{T}_{\text {. }}=21^{\circ} \mathrm{C}\left(70^{\circ} \mathrm{F}\right)
$$

6. Compartment

$$
H_{v}=2.03 \mathrm{~m}\left(80^{\prime \prime}\right) ; W_{v}=.74 \mathrm{~m} ; A_{v}=1.5 \mathrm{~m}^{2}
$$

Now that we have an upper layer gas temperature required to decomposi the PTFE cabling, we can estimate the fire size necessary to produce this temperature for an assumed compartment size using the relation derived by Quintiere. ${ }^{9}$ Rearranging Equation 16 from the Quintiere paper, we obtain the following expression:

$$
\left(\frac{\mathrm{T}_{U L}-\mathrm{T}_{a}}{6.85}\right)^{3}=\frac{\dot{\mathrm{Q}}_{f}^{2}}{\left(\mathrm{~A}_{v} \sqrt{\mathrm{H}_{v}}\right)\left(\sum_{s}\left[\mathrm{~h}_{k} \mathrm{~A}\right]_{s}\right)} .
$$

In this expression, $A_{v} \sqrt{H_{v}}$ is the ventilation parameter (vent area multiplied by the square root of vent height, in $\mathrm{m}^{2}$ and $\mathrm{m}$, respectively). For a typical doorway of $2.03 \mathrm{~m}$ high by $0.74 \mathrm{~m}$ wide, the ventilation parameter equals $2.13 \mathrm{~m}^{5 / 2}$. The other term in the denominator of the righthand side of the equation relates to the conductive heat losses to the compartment surfaces. For these steady state (long time) calculations, $h_{k}=k / \ell$ where $k$ is the thermal conductivity $\left(\mathrm{kW} / \mathrm{m}^{\circ} \mathrm{K}\right), \ell$ is the tile thickness $(\mathrm{m})$, and $A$ is the surface area $\left(\mathrm{m}^{2}\right)$. Since the walls, ceiling, and floor are generally constructed of different materials, $h_{k} A$ is computed individually for each material and summed.

Since Equation 12 has three unknown terms; the ventilation parameter $\left(A_{v} \sqrt{H_{v}}\right)$, conduction loss $\left(\sum_{s}\left[h_{k} A\right]_{s}\right)$, and the fire heat release rate $\left.\dot{Q}_{\jmath}\right)$, one must select any two to calculate the third. There will probably be only a few possible ventilation parameters (single door, double door, etc.) consistent with the room size. Also, for estimating purposes we might assume a square room of height $H$ such that the wall area equals $4 \mathrm{WH}-\left(\mathrm{A}_{v}\right)_{\text {taral }}$ and the floor and ceiling areas are each $W^{2}$.

To demonstrate the sensitivity of these numbers to the decomposition 
temperature selected, they were recalculated assuming a decomposition temperature of $325^{\circ} \mathrm{C}\left(617^{\circ} \mathrm{F}\right)$. For this case, the results are

$$
\begin{array}{rlrl}
\mathrm{T}_{3} & =241^{\circ} \mathrm{C}\left(465.8^{\circ} \mathrm{F}\right) & \mathrm{T}_{1}=325+\frac{.84 \ell}{\mathrm{k}_{\mathrm{l}}} \\
\mathrm{T}_{4}=148^{\circ} \mathrm{C}\left(298.4^{\circ} \mathrm{F}\right) & \\
\mathrm{T}_{3}=110^{\circ} \mathrm{C} & \mathrm{T}_{U L}=\mathrm{T}_{1}+84 \\
\dot{\mathrm{q}}^{\prime \prime}=0.84 \mathrm{~kW} / \mathrm{m}^{2} &
\end{array}
$$

\section{EXAMPLE CALCULATIONS}

We will first consider a 1 in. $(25.4 \mathrm{~mm})$ mineral fiber ceiling tile with a typical thermal conductivity of $0.16 \times 10^{-3} \mathrm{~kW} / \mathrm{m}-{ }^{\circ} \mathrm{K}$. Inserting these values in Equations 10 and 11, we obtain values for the ceiling tile lower surface temperature and upper layer gas temperature of $725^{\circ} \mathrm{C}$ and $867^{\circ} \mathrm{C}$ $\left(1337^{\circ} \mathrm{F}\right.$ and $\left.1593^{\circ} \mathrm{F}\right)$, respectively. Now, substituting the calculated upper layer temperature into Equation 12 and assuming an ambient temperature of $21^{\circ} \mathrm{C}\left(70^{\circ} \mathrm{F}\right)$ we obtain the expression:

$$
\frac{\dot{\mathrm{Q}}_{f}^{2}}{\left(\mathrm{~A}_{v} \sqrt{\mathrm{H}_{v}}\right)\left(\sum_{s}\left[\mathrm{~h}_{k} \mathrm{~A}\right]_{s}\right)}=1.88 \times 10^{6}
$$

\section{Case I}

For a typical $3 \mathrm{~m}$ (10 ft) ceiling height and a single door $\left(1.5 \mathrm{~m}^{2}\right.$ area), the expréssion for the room wall area (for,a square room) is $12 \mathrm{~W}-1.5$. Using a ventilation parameter of $2.13 \mathrm{~m}^{3 / 2}$ and selecting a room $10 \mathrm{~m}$ square with $1 / 2$ in. $(12.7 \mathrm{~mm})$ gypsum walls $\left(\mathrm{k}=0.17 \times 10^{-3} \mathrm{~kW} / \mathrm{m}-{ }^{\circ} \mathrm{K}\right), 2$ in. $(50.8 \mathrm{~mm})$ concrete floor $\left(\mathrm{k}=1.6 \times 10^{-3}\right)$, and the $1 \mathrm{in}$. $(25.4 \mathrm{~mm})$ thick mineral ceiling tile, we can solve Equation 12 for the fire heat release rate necessary to just raise the wire insulation to its decomposition temperature in this compartment. This results in a calculated heat release rate of $4637 \mathrm{~kW}$. For the $325^{\circ} \mathrm{C}\left(617^{\circ} \mathrm{F}\right)$ decomposition temperature, $\mathrm{T}_{1}$ and $\mathrm{T}_{U L}$ would be $452^{\circ} \mathrm{C}$ and $534^{\circ} \mathrm{C}\left(846^{\circ} \mathrm{F}\right.$ and $\left.993^{\circ} \mathrm{F}\right)$, respectively and the calculated heat release rate would be $2192 \mathrm{~kW}$.

\section{Case II}

For comparison, we can conduct the same calculations for a $1 / 2$ in. $(12.7 \mathrm{~mm})$ thick glass fiber material with a typical thermal conductivity of $0.4 \times 10^{-3} \mathrm{~kW} / \mathrm{m}-{ }^{\circ} \mathrm{K}$. In this case, we obtain $\mathrm{T}_{1}$ and $\mathrm{T}_{U \iota}$ of $545^{\circ} \mathrm{C}$ and $687^{\circ} \mathrm{C}\left(1013^{\circ} \mathrm{F}\right.$ and $\left.1269^{\circ} \mathrm{F}\right)$, respectively. Inserting the calculated upper layer temperature into Equation 12 and assuming the same $10 \times 10 \times 3 \mathrm{~m}$ room with gypsum walls, concrete floor, and a single door, we obtain a calculated heat release rate necessary to raise the wire in this system to its decomposition temperature of $3930 \mathrm{~kW}$. 
An interesting comparison would be to compare these calculated heat release rates with the minimum energy required to flashover the compartments of interest, using the flashover equation from Thomas: ${ }^{10}$

$$
\dot{\mathrm{Q}}_{f_{0}}=378 \mathrm{~A}_{v} \sqrt{\mathrm{H}_{v}}+7.8 \mathrm{~A}_{T}
$$

where $A_{T}$ is the total surface area of the compartment $\left(\mathrm{m}^{2}\right)$.

In both cases, the ventilation factor is $2.13\left(\mathrm{~m}^{5 / 2}\right)$ and the wall areas have been previously calculated, we obtain a minimum flashover energy for the $10 \mathrm{~m}$ square room of $3289.44 \mathrm{~kW}$. This tells us that in both cases calculated for the $500^{\circ} \mathrm{C}\left(932^{\circ} \mathrm{F}\right)$ decomposition temperature, the energy release rate necessary to raise the wire to its decomposition temperature is from 1.2 to 1.4 times that necessary to flashover the compartment. That is, even at flashover, the wire will not be raised to its decomposition temperature unless the heat release rate continues to increase by a further one and a half times. If a $325^{\circ} \mathrm{C}\left(617^{\circ} \mathrm{F}\right)$ decomposition temperature is assumed, the required energy is about two thirds of the required flashover energy. However, since radiative heat transfer was neglected in the steady state calculation, one would expect that the heat release rate necessary to raise the wire to its thermal decomposition temperature would be less than the values calculated, although the primary effect of the inclusion of radiation is to reduce the time to reach a given temperature rather than on the steady state temperature reached.

\section{LIMITATIONS OF THE CALCUL̈ATION}

In addition to neglecting radiation and energy lost from the plenum space by forced convection or thermal expansion, there are several other major limitations to this calculation which should be mentioned. This steady state calculation assumes a constant heat release rate and does not take into account temperature spikes which might be created from peaks in the heat release curve of an actual combustible material. Also, we have assumed the heat transfer to the suspended ceiling is from a hot upper gas layer of uniform temperature. We have not taken into account the hot spot that would form on the ceiling above the fire plume. This hot spot would cause an area on the suspended ceiling of substantially higher temperature producing localized decomposition of the wire insulation even though the average upper gas temperature was below that necessary to raise the entire top surface of the tile to that temperature. These are factors which can and will be addressed in computer fire model calculations to be conducted later.

The previous calculations show that it is possible to have a fire in the compartment below which will produce temperatures above the wire insula. tion decomposition temperature at the top surface of the ceiling. In this case, the potential toxicity of the wire insulation material becomes important. In order to assess this potential toxicity, one needs to know the $\mathrm{LC}_{\text {so }}$ value (from a toxicity test method $^{3}$ ) for a given exposure time, the mass loss 
rate of the wire insulation material at its decomposition temperature, and the volume into which the decomposition products will be distributed.

Now we can estimate mass loss for each of the above cases. Let us begin with the fire first.

\section{BURNING FURNISHINGS MASS LOSS}

The mass loss rate of a material can be estimated by dividing its heat release rate $(\mathrm{kW})$ by its effective heat of combustion $(\mathrm{kJ} / \mathrm{g})$. In this case heats of combustion range between $20-40 \mathrm{~kJ} / \mathrm{g}$. Thus the mass loss rates for our two cases:

$$
\mathrm{KW}=\mathrm{kJ} / \mathrm{sec}
$$

Case I: $4637 \mathrm{~kW}$ [ 1 in. $(25.4 \mathrm{~mm})$ thick mineral tile ceiling]

$$
\text { mass loss },=116-232 \mathrm{gm} / \mathrm{sec} \text {. }
$$

Case II: $3930 \mathrm{~kW}$ [1/2 in. $(12.7 \mathrm{~mm})$ glass fiber material]

$$
\text { mass } \text { loss }_{\| t}=98-196 \mathrm{gm} / \mathrm{sec} \text {. }
$$

\section{PTFE MASS LOSS}

PTFE will lose approximately 1 percent of its mass per minute at a temperature of $510^{\circ} \mathrm{C}\left(950^{\circ} \mathrm{F}\right) .^{\prime}$ Thus,

$$
\text { mass loss } \text { PTFE }=.01 / 60=.000167 \mathrm{gms} / \mathrm{sec} / \mathrm{gm} \text {. }
$$

\section{Smoke Concentration}

Let's now assume the products of combustion from the scenario of concern are distributed into a $1000 \mathrm{~m}^{3}$ volume - a space several times the volume of the compartment of fire origin. We can then calculate the rate at which the mass concentration of products from the fire and from the decom. position of the PTFE will increase in this volume.

Case I: $116 \frac{\mathrm{gm}}{\mathrm{sec}} \times \frac{1}{1000 \mathrm{~m}^{3}}=.116 \mathrm{mg} / \mathrm{l}-\mathrm{sec}$.

Case II: $98 \frac{\mathrm{gm}}{\mathrm{sec}} \times \frac{1}{1000 \mathrm{~m}^{3}}=.098 \mathrm{mg} / \ell-\mathrm{sec}$.

PTFE: $.000167 \frac{\mathrm{gm}}{\mathrm{sec}} \times \frac{1}{1000 \mathrm{~m}^{3}}-\mathrm{gm}=1.67 \times 10^{-7} \mathrm{mg} / \ell-\mathrm{sec} / \mathrm{gm}$.

\section{Estimate Consequences}

Now let's examine the relative toxicities of these materials: 
Assume -

$$
\text { Case I } \sim \text { Case II } \approx \mathrm{LC}_{50} \sim 40 \mathrm{mg} / \mathrm{l} .
$$

It would take approximately

$$
\begin{aligned}
& t_{l}=40 / .116=345 \mathrm{sec} \\
& t_{I I}=40 / .098=408 \mathrm{sec}
\end{aligned}
$$

to create lethal smoke concentrations in the $1000 \mathrm{~m}^{3}$ volume. Assume: $\mathrm{LC}_{50}$ for PTFE $\approx .05 \mathrm{mg} / \ell$. Then for PTFE it would take

$$
\text { PTFE } .05 / 1.67 \times 10^{-7}=.0299 \times 10^{7}=30 \times 10^{4} \mathrm{sec} / \mathrm{gm}
$$

plus the time required to heat the upper surface of the ceiling tile to the wire decomposition temperature. That is, while the fuel in the compartment below contributes toxic products from the time of ignition, the cable insulation does not begin to contribute until it reaches its decomposition temperature. While calculating the time to reach this temperature on the upper surface of the tile is too difficult for a hand calculation, a "worst case" estimate can be made by calculating the thermal penetration time $\left(t_{p}\right)$ for the ceiling tile. This is the time required for thermal energy to be conducted through the material and represents the time for the upper surface temperature to begin to rise above ambient. From Quintiere ${ }^{9}$ this relation is:

$$
\mathrm{t}_{p}=\frac{\varrho \mathrm{C}_{p}}{\mathrm{k}}\left(\frac{\ell}{2}\right)^{2}
$$

For the mineral tile case calculated and assuming $50 \mathrm{lb} *\left(22.5 \times 10^{3}\right.$ grams $)$ of PTFE in the ceiling space the estimated hazard time is:

$$
\mathrm{t}_{\text {PTFE }}=\left(\frac{30 \times 10^{4}}{22.5 \times 10^{3}}\right)+\left(\frac{385(1.06)}{.16 \times 10^{-3}}\right) \times\left(\frac{2.54 \times 10^{-2}}{2}\right)^{2}=425 \mathrm{sec}
$$

which would be at about the same time as the entire volume is rendered lethal by the initiating fire. But additional time beyond the thermal penetration time would be required for the top surface to rise to $500^{\circ} \mathrm{C}\left(952^{\circ} \mathrm{F}\right)$. This is illustrated in Figure 2 which shows the effect of assuming a step function for the temperatures (as in this calculation) compared to the actual case where the temperatures would increase exponentially.

This "actual time to start of PTFE decomposition" can be estimated from a conduction calculation on a symmetrical geometry assuming zero

* $50 \mathrm{lb}$ of PTFE insulation might typically be found in $1000 \mathrm{ft}$ of $12 / 2$ or $500 \mathrm{ft}$ of \#12/6 cable. 
heat loss from the tile during transient heating. Assume a ceiling tile of thickness $2 \ell$, heated to temperature $T_{1}\left[725^{\circ} \mathrm{C}\left(1337^{\circ} \mathrm{F}\right)\right.$ for Case I] on both surfaces. The time of interest is then the time for the center of this tile to reach $500^{\circ} \mathrm{C}\left(932^{\circ} \mathrm{F}\right)$. From the Carslow and Jaeger reference. ${ }^{\prime \prime}$

$$
\frac{\nu c}{V}=\frac{500+273}{725+273}=0.775
$$

and from their Figure 12, read $\frac{\alpha \text { t }}{\ell^{2}}=0.7$

$$
\mathrm{t}=0.7 \frac{6.45 \times 10^{-4}}{0.39 \times 10^{-6}}=1158 \mathrm{sec} \text {. }
$$

Thus, the estimated hazard time for the assumed $50 \mathrm{lb}$ of PTFE in the ceiling space is:

$$
t_{\text {PTFE }}=\left(\frac{30 \times 10^{4}}{22.5 \times 10^{3}}\right)+1158=1171 \mathrm{sec}(19.5 \mathrm{~min}) .
$$

From the above it is seen that potentially lethal conditions would be reached beyond the compartment of fire origin due to the compartment fire well before there is any contribution of PTFE in the suspended ceiling. Also we've noted that typically for thermally insulating ceilings, the energy

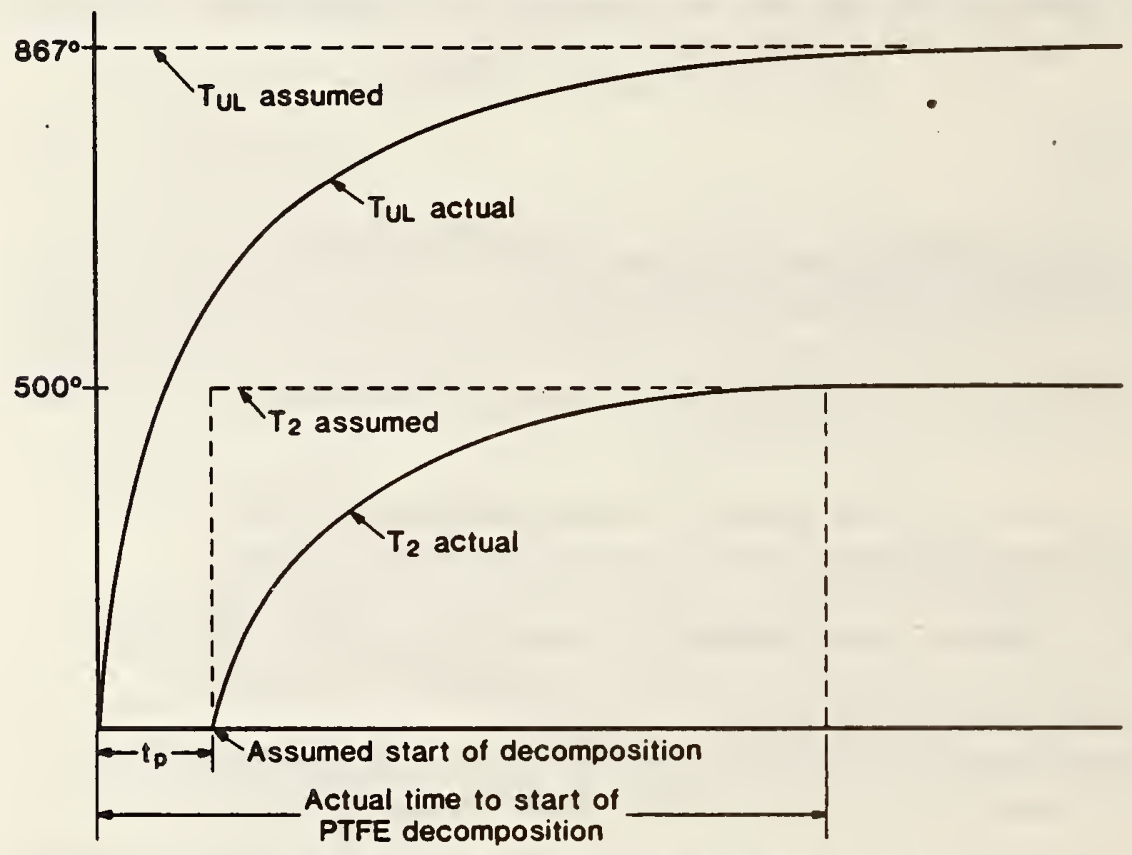

Figure 2. System thermal response for Case I example with $\dot{Q}=4637 \mathrm{~kW}$ (not to scale). 


\section{Plenum Cables}

levels required to decompose the PTFE are in excess of those required to flashover the compartment of fire origin as long as the ceiling maintains its structural integrity. After flashover, the relative contribution of the PTFE to the overall smoke hazard would diminish markedly as the full mass of compartment contents became involved. Clearly, the thermal protection provided by the suspended ceiling is a critical factor in limiting the level of hazard which might be posed by the cable in this scenario. The analysis is conservative because (a) the assumed thermal contact between the ceiling tile and the cable would almost certainly not be fully realized in practice, (b) the assumed static air in the plenum would not spread cable effluents to other parts of the building (on the other hand, moving air would reduce plenum temperature and moderate ceiling and cable temperatures), and (c) the toxicity value used for PTFE in this analysis was the most toxic value cited in the literature. There is some evidence that the effective toxicity of PTFE decomposition products may be substantially reduced when mixed with combustion products from other materials. ${ }^{12}$ While observations in this regard are influenced by experimental procedure, ${ }^{13}$ there remains a significant prospect that the effective toxicity may be markedly lower than the apparent value used in this analysis, ${ }^{14}$ and additional research is needed to clarify this point.

\section{ALTERNATIVES: FIRE RATED CEILING ASSEMBLIES}

Current codes do not require plenum spaces used for environmental air to use fire rated floor/ceiling assemblies. However, if fire rated floor/ceiling assemblies are to be used for environmental air, they are tested with the supply and return air grills in place although the system is static in air flow. ${ }^{15}$ Under these conditions when tested per NFPA 251, Standard Method of Fire Tests of Building Construction and Materials, the assembly is considered to fail when the unexposed surface temperature rise $\left(T_{3}\right)$ exceeds $139^{\circ} \mathrm{C}\left(282^{\circ} \mathrm{F}\right)$ or if the temperature on steel structural components within the plenum space reaches $704^{\circ} \mathrm{C}\left(1300^{\circ} \mathrm{F}\right)$ at any single point or an average of $594^{\circ} \mathrm{C}\left(1100^{\circ} \mathrm{F}\right) .^{15}$ Since this average temperature is very close to the thermal decomposition temperature of the wire insulation, this says that, under the severe fire exposure conditions of this test method, the wire insulation would not be expected to reach its decomposition temperature for most of the relevant time period. Thus, an alternative solution for uses where concerns remain over toxicity of plenum cables might be to require rated assemblies where unprotected plenum cables are used. Even then, further calculations using computer fire models to evaluate the potential problems caused by the hot spot over the fire plume, forced convection, and the relative importance of conduction through the suspended ceiling grid system would be desirable.

\section{REFERENCES}

'Snell, J. E. et al., Summary Preliminary Report of the Advisory Committee on the Toxicity of the Products of Combustion, NFPA 1984. 
${ }^{2}$ Standard on Air Conditioning and Ventilating Systems, NFPA 90A-1981.

${ }^{3}$ Levin, B. C. et al, Further Development of a Test Method for the Assessment of the Acute Inhalation Toxicity of Combustion Products, NBSIR 82-2532.

4 International Standards Organization Technical Report 6543, Ref. No. ISO/TR 6543-1979 (E).

${ }^{s}$ Punderson, J. O., "A Closer Look at Cause and Effect in Fire Fatalities - The Role of Toxic Fumes," Fire and Materials, Vol. 5, No. 1, 41-46, 1981.

'Doe, J. E., and Woolley, W. D., Discussion Paper on Toxic Hazards in Fire, International Standards Organization Document ISO/TC92/WG12 - N99, 1981.

'Combustion Toxicity of Fire Effluents: The State of the Art 1984, International Stan. dards Organization Document ISO/TC92/SC3/WG4 - N26.

Madorsky, S. L., Thermal Degradation of Organic Polymers, John Wiley and Sons, 1964.

Q Quintiere, J. Q., A Simple Correlation for Predicting Temperature in a Room Fire, NBSIR 83-2712.

10 Thomas, P. H., "Testing Products and Materials for Their Contribution to Flashover in Rooms," Fire and Materials, Vol. 5, 103-111 (1981).

"Carslaw and Jaeger, Conduction of Heat in Solids, 2nd Ed., Oxford University Press, $102,1959$.

${ }_{12}$ Williams, S. J., and Clarke, F. B., "Combustion Product Toxicity: Dependence on the Mode of Product Generation," Fire and Materials, Vol. 6, Nos. 3 and 4, 161-162, 1982.

${ }_{13}$ Alarie, Y., and Stock, M. S., Fire and Materials, "Letter to Editor" Vol. 8, No. 1, 54-55, 1984.

${ }_{14}$ Williams, S. J., and Clarke, F. B., Fire and Materials, "Reply to Letter to Editor" Vol. 8, 55, 1984.

${ }^{15}$ Standard Methods of Fire Tests of Building Construction and Materials, NFPA 251-1983. 
APPENDIX B

- EVALUATION OF FURNITURE FIRE HAZARD

USING A HAZARD ASSESSMENT COMPUTER MODEL 
Evaluation of Furniture Fire Hazard Using a Hazard Assessment Computer Model Richard W. Bukowski, P.E., Research Head*

Smoke Hazard

Center for Fire Research

National Bureau of Standards

Gaithersburg, Maryland 20899

\section{BACKGROUND}

Over the past decade, the field of computer fire modeling has been advanced to the point that reasonably accurate predictions of the consequences of fire in a structure can be made. While refinements in the capabilities of these models and validation of their predictive accuracy are the subjects of ongoing research, it is felt that they have advanced to the point that they can be used at least to provide comparative evaluation of hazard mitigation strategies within their current limits of applicability. The purpose of this paper is to demonstrate how a specific hazard model might be used to identify the most promising hazard mitigation strategy for a specific scenario of general interest.

Fires in residential occupancles accounted for some $80 \%$ of all civilian fire deaths, $70 \%$ of injuries, and $57 \%$ of property loss in calendar year 1983 [1]. For the nation as a whole, statistics indicate that upholstered furniture is most of ten the first item ignited in fatal residential fires.

*This paper is a contribution of the National Bureau of Standards and 15 not subject to copyright. 
Recognizing this fact, the furniture industry, through the Upholstered Furniture Action Council (UFAC) has developed and implemented a voluntary program intended to reduce the likelihood of the ignition of upholstered furniture items by dropped cigarettes [2]. While this program has been recently shown to be reasonably successful in reducing the likelihood of ignitions, it can never eliminate them, nor does it necessarily impact the likelihood of ignition from a flaming source nor the resulting hazard when any ignition occurs. In fact, thermoplastic cover fabrics which have good cigarette ignition resistance often exhibit a lower resistance to ignition by small flaming sources [3]. Thus, one logical step in making upholstered furniture safer might be to examine the potential benefits of material selection or modification in reducing the hazards of furniture fires given an ignition.

The hazards to building occupants from a fire involve the exposure to heat, toxic combustion products, and smoke which obscures vision and delays or prevents escape. The time available for the occupants to escape varies as a function of a number of parameters, only some of which can be controlled, for example in this case, by a furniture manufacturer. Thus, the purpose of the following evaluation was to estimate the potential benefit of a variation in a controllable parameter relative to the variation which might be expected due to the parameters which cannot be controlled by the product producer such as the room size or construction of the house into which the item is placed. By the use 
of relative comparisons, the effect of systematic errors due to the Imitations in modeling capabilities should be minimized.

2. Fire (Toxic) Hazard Model

The Center for Fire Research (CFR) has an ongoing project to develop quantitative methods for assessing fire and smoke toxicity hazards based primarily on computer fire modeling techniques. Recently, the first generation hazard model developed by Walter Jones has been published [4]. This model (called FAST) can predict the generation, transport, and effect of heat, smoke, and a number of specific toxic gas species in up to 8 interconnected compartments on a single floor of a structure. This is the hazard assessment model used for this evaluation. Details on this model and the CFR hazard assessment program are contained in other published works $[4,5]$ and will not be repeated here.

User-selectable input parameters to this model include the size and geometric relationship of the compartments in the structure, the thermal properties of the wall and ceiling materials used in the structure, and the combustion characteristics of the combustible contents (fuel). It is therefore a simple matter to vary any of these parameters individually or in combination and determine the effect on hazard (see section 4). 


\section{Scenario Selection}

For the present case, the basic scenario to be evaluated involves the combustion of a single piece of upholstered furniture exposed to a flaming ignition source in the living room of a single floor residential structure. This living room is at one end of a $9 \mathrm{~m}$ (30 foot) long hallway with a bedroom at the other end of the hallway (see Fig. 1). Only these three compartments were considered in the calculation, representing the case where any other compartments in the residence had tightly-fitting, closed doors. For the base case, the room dimensions, construction materials, and geometric arrangements of the compartments were taken from an actual residential structure used in a series of smoke detector experiments conducted in 1975 [6]. The only exception was that the area of the living room was reduced by a factor of 2 for the base case since this actual structure had an unusually large living room. Since one of the variant cases examined was for a living room of twice the area of the base case, the actual structure was included in one of the cases examined.

In order to examine the impact of fire size, three upholstered furniture items were considered. These were an upholstered chair, love seat, and sofa for which test data were obtained from Babrauskas [7]. These three items were actual furniture items acquired as a set and constructed of identical materials, varying only in size and mass. The heat release curves for these three items are shown in Fig. 2. It was assumed that 
the burning behavior of these items would be the same in the room as was measured [9]. The input data used for the base case are detailed in Table 1.

After selection of the fuel items, the matrix of parameter variations shown in Table 1 was constructed. As can be seen in the table, the varied parameters include the size of each of the compartments, wall material and the effect of closing the bedroom door, (which represent uncontrollable parameters from the perspective of the furniture manufacturer); and vartation in fuel parameters including the heat of combustion, smoke release, and burning rate (which represent factors which can be controlled by the furniture manufacturer). Since the parameters were varied one at a time from the base case, this resulted in a total test matrix of 33 model runs.

Also examined for each case was the effect of increasing or decreasing the effective "combustion product toxicity" of the furniture item. Due to the way this is calculated in the hazard model, this variation could be examined without the need for separate computer runs.

\section{Hazard Analysis}

Once the parameter variation matrix had been established, the input f1les were created and the 33 model runs were batch processed over one weekend. 
This produced 33 data files which are very similar to the data file produced by a data acquisition system for a full scale fire experiment. That is, the file contains values for each of the following parameters for each 10 seconds (this time is selectable as an input parameter to the model) of simulated fire time.

1. Upper Layer Temperature

2. Lower Layer Temperature

3. Height (Above the Floor) of the interface between layers

4. Optical Density in the Upper Layer

5. Fractional Lethal Dose in the Upper Layer

6. Carbon Monoxide Concentration in the Upper Layer*

Each calculated parameter is essentially a bulk average value within a homogeneous layer-an assumption inherent in zone models.

Example plots of items 1, 2, and 3 for the base case, loveseat runs are presented in figures 3 through 5. Figure 6 gives the toxic products mass concentration versus time for the same case; the fractional lethal dose would be obtained by dividing this concentration by $32 \mathrm{mg} / \ell$ for a $30 \mathrm{~min}$. exposure.

* These values were computed but, since the toxicity was judged by Fractional Lethal dose, these data are not presented here. 
The model calculates a number of additional parameters which will not be discussed because they were not included in this evaluation. A complete discussion of all of the parameters calculated is included in the report on the model [4].

The examined parameters are all straightforward except for fractional lethal dose which is described as follows.

The NBS Toxicity Test Method has been used to develop LC $_{50}$ values for a number of simple materials. This $\mathrm{LC}_{50}$ is the mass of fuel loaded into the combustion chamber divided by the volume into which the combustion products are released, for which $50 \%$ of the test animals exposed to these combustion products died during either the 30 minute exposure period or a 14 day post-exposure observation period. A thorough discussion of the test method and procedures is contained in reference [8].

Currently, data are available only on individual materials. But the upholstered furniture items considered in this evaluation are constructed of a synthetic upholstery fabric, polyurethane foam, and a wooden frame. Therefore, an effective $\mathrm{LC}_{50}$ was calculated by taking estimated $\mathrm{LC}_{50}$ values for the fabric, foam, and wood and calculating a "mass welghted average value" as follows: 


$$
\frac{1}{\overline{L C}_{50}}=\sum_{i} \frac{f_{i}}{L_{50}}
$$

where: $f_{i}$ is the fraction of the total item mass represented by material $i$ $\mathrm{LC}_{50}$ is the 30 min $\mathrm{LC}_{50}$ of material $i$

Since, for all three items the wood frame was about $25 \%$ of the total mass, the foam about $65 \%$ of the mass (both $\mathrm{LC}_{50}$ 's $\sim 40 \mathrm{mg} / \hat{\imath}$ ) and the fabric the remaining $10 \%\left(\mathrm{LC}_{50} \sim 12 \mathrm{mg} / \mathrm{l}\right)$ the effective $\mathrm{LC}_{50}$ used for all three items was $\sim 32 \mathrm{mg} / \mathrm{l}$. While we recognize that $\mathrm{LC}_{50}$ 's are not necessarily additive, this is the only means currently available to deal with multiple materials. For a discussion of the steps being taken to address this problem, see Ref 5 .

The model then calculates a fractional lethal dose at any given time by taking the total fuel mass lost to that point in time, distributing that mass into the three compartments consistent with the complex flow phenomenona contained in the model, and then dividing by the volume of the upper layer to obtain a mass concentration. The fractional lethal dose is then simply this computed mass concentration divided by the effective $\mathrm{LC}_{50}$ (32 $\mathrm{mg} / \mathrm{l}$ in this case) for a 30 minute exposure. In fact, it represents an exposure concentration rather than a true dose since it does not directly consider the uptake over time; which would be the area under the concentration curve.

The next step in the analysis was selection of hazard criteria. For each of the calculated conditions, 2 or 3 values were selected as representing 
limiting conditions for that parameter. Some people may argue with the values selected, but because the evaluation was done on a comparative basis, selecting different hazard criteria in most cases should have only a minimal effect on the relative results. Human tolerance to anything varies widely, and other values might be appropriate for other purposes depending on the projected capabilities of the occupants and the degree of conservatism desired. In any case, the values used in this evaluation are:

1. Temperature; $66^{\circ} \mathrm{C}$ and $100^{\circ} \mathrm{C}$

2. Interface Height (from the floor); $1.5 \mathrm{~m}$ and $1 \mathrm{~m}$

3. Optical Density; 0.25 and $0.5 \mathrm{~m}^{-1}$

4. Fractional Lethal Dose; $0.5,1.0$, and 1.5

For each of the 33 model runs conducted, the time to reach each of these hazard criteria in each of the compartments was tabulated. The percent change from the base case ( + or - ) for each of these times was then calculated. These data for the chair simulations are contained in Table 2 . The percent change from the base case for each calculated condition gives an assessment of the value of the change of that parameter relative to both the base case and to each other. This allows both estimates of the hazard reduction potential for controllable parameters and a method of comparing them to the variation which might be expected from variations in uncontrollable parameters. 


\section{Results}

A narrative discussion of the trends observed in the data relative to the base condition follows, for each of the cases studied. Cases involving parameters which would not be controllable by the manufacturer of an upholstered furniture item will be discussed first.

Doubling the area (and hence the volume) of the living room produces a small positive effect (longer time to reach critical conditions) for the upper and lower layer temperatures, optical density, and fractional lethal dose. The effect on the time at which the lowering interface height becomes hazardous is also positive and somewhat greater in magnitude. In all cases, these effects tend to be either the same or slightly greater for the larger combustible items and slightly smaller

- in magnitude for the bedroom as compared to the living room.

Reducing the length of the hallway by a factor of 2 results in less time to escape for all hazard criteria examined except for the lower layer temperature, which did not rise as quickly. The magnitude of all of these changes was relatively constant for all three compartments and independent of the size of the combustible item.

Doubling the area of the bedroom had a small positive effect on all parameters (particularly in the bedroom), the magnitude of which was 
relatively consistent with fuel mass.

Changing the wall materials from a wood paneling to a gypsum board had no measurable effect on any of the calculated parameters compared to the base case. This is because of the fact that wood paneling has very similar thermal properties to gypsum board, and both were assumed not to contribute to the fire.

Closing the door to the bedroom during the fire (but allowing some leakage) tended to produce a small to moderate positive effect within the bedroom with a small negative effect in the other 2 compartments. As one would expect, the closed (but leaky) door delayed the entrance of heat and smoke into the bedroom. Conversely, the decrease in the remaining volume into which the mass and energy being released by the fire could spread decreased the time to hazard in the other compartments.

Summarizing the effect of the uncontrollable parameters, it can be seen that increasing or decreasing the size of the compartments produced positive and negative effects respectively on the time to reach hazardous conditions. The most important observation is that the magnitude of these effects tends to be small (on the order of $10 \%$ to $15 \%$ ) for changes in area of a factor of 2. Thus, if variations in controllable parameters produce more than a $10 \%$ to $15 \%$ increase in time to hazard, the benefit of such a change would be experienced regardless of the residence in which the item is used, assuming the room sizes will not vary by much more than a factor of 2 in most cases. With this in mind, it is possible to discuss the effects of the parameters which can be controlled by material selection or modification. 
The heat of combustion of a material is a measure of the potential energy released when burned, and is not a property which can be modified. A furniture manufacturer can, however, select a different material with a different heat of combustion. Either increasing or decreasing the heat of combustion by a factor of 2 produced small changes in the hazard time associated with interface height, optical density, and fractional lethal dose. For upper and lower layer temperatures, however, the observed effect on time to hazard was moderate (increasing for decreasing the heat of combustion and decreasing for increasing the heat of combustion). This is a reasonable result, since the heat of combustion would be expected to affect temperature directly with a secondary effect on interface height from the reduced buoyancy of the gases in the upper layer.

Conversely, variations in the smoke yield of the material shows no effect on the upper and lower layer temperatures, interface height, and fractional lethal dose. It did have a small to moderate effect on the time to reach a critical value of optical density. This smoke fraction is the fraction of original fuel mass which is released into the air as smoke, and is a parameter which can be modified by use of "low smoke" materials. Some work is being done on smoke suppressant chemical additives, but their performance is yet to be clearly demonstrated. Of more importance to the current consideration is the fact that the addition of fire retardant chemicals to retard a material's burning rate sometimes has the effect of increasing the smoke yield of the material. In fact, changes in the smoke mass concentration in the upper layer will have an effect on the temperature since more mass will absorb radiant energy raising the layer temperature. The current version of the model does not include this 
effect. From experimental data it is felt that the impact of inclusion of absorption would not change the conclusions of this analysis.

The final parameter variation was a reduction in the mass loss (burning) rate. In the present case the mass loss rate was decreased by a factor of two but the total burning time was doubled so that the total energy released was the same as the other cases. This would typically be done by selection of materials that have inherently slower burning rates or by the addition of fire retardant chemicals and inert fillers to a given material, although the amount necessary to be effective is generally large. In this analysis, this parameter was clearly the most desirable parameter evaluated in terms of its beneficial effect on hazard times. It produced a large (factor of 2 to 3 times) increase in time to hazard due to upper and lower layer temperature, optical density and fractional lethal dose, with a moderate (approximately 50\%) increase in troe to hazard due to interface height. For this case, the net gain is so much greater than for any of the other parameters that a net positive effect would be expected regardless of the size of the rooms and even if the fire retardant chemical or optional material used produced twice as much smoke and was twice as toxic.

\section{Summary}

In summary, the evaluation described herein results in the following conclusions:

1. Variations in room size by a factor of 2 produced small changes in hazard time, generally less than a $50 \%$ change relative to the base case. 
2. A closed bedroom door increased time to hazard within the bedroom on the order of 30 to $60 \%$ (which will vary with the crack size assumed), but decreased time to hazard in the other rooms due to the smaller volume into which the mass and energy is distributed.

3. Variations in heat of combustion and smoke fraction produced small changes in time to hazard from temperature $(<60 \%)$ and interface height $(<25 \%)$; and visibility $(<60 \%)$, respectively.

4. Decreasing the mass loss (burning) rate by a factor of 2 produced a large increase in time to hazard (100-200\%) for temperature, smoke density and toxicity, and a small (30-70\%) increase in time to hazard from interface height.

\section{Observations}

It was also noted that the time to reach hazardous conditions in these model predictions was consistant with that observed in the actual, fullscale experiments conducted by burning single items of upholstered furniture in the house from which the room geometries were taken [6].

The hazard analysis procedure described here is intended to demonstrate how hazard models currently under development can be used to evaluate the potential benefits of and identify research priorities for reducing fire hazards and losses. Until these models are validated, their results should not be considered quantitative but rather should be used to identify 
promising areas for further research. With this as a guide, material producers and furniture manufacturers can explore new materials and techniques and verify the benefits through more traditional small and large scale fire testing programs. Eventually, as these models become statistically validated, it may be possible to obtain quantitative information with sufficent confidence to require little or no proof testing. For now, it is hoped that this paper has demonstrated the benefit of using these models to narrow the field of potential hazard reduction strategies to those which can be expected to provide the maximum benefit. 
1. Karter Jr., M. J. and Gancarski, J. L., Fire Loss in the United States During 1983, Fire Journal, Vol. 78, No. 5, 48-67, Sept. 1984.

2. Upholstered Furniture Action Council, Furniture Flammability: Reducing the Hazard, UFAC, High Point, N.C., Sept. 1982.

3. Krasny, J. F. and Babraukas, V., Burning Behavior of Upholstered Furniture Mockups, J. of Fire Sciences, Vol 2, No. 3, 205-235, May/June 1984.

4. Jones, W. W., A Model for the Transport of Fire, Smoke, and Toxic Gases (FAST), Nat. Bur. Std. (U.S.) NBSIR 84-2934, Sept. 1984.

5. Bukowski, R. W. and Jones, W. W., Development of a Method for Assessing Toxic Hazard, Fire Journal, Vol 79, No. 2, 24-29, 82, March, 1985.

6. Bukowski, R. W., Waterman, T., and Christian, W. J., Detector Sensitivity and Siting Requirements for Dwellings, Nat. Bur. Std. (U.S.) NBSGCR 75-51, Aug. 1975. 
7. Babrauskas, V., Upholstered Furniture Heat Release Rates: Measurements and Estimation, I of Fire Sciences, 1, 9-32, Jan/Feb 1983.

8. Levin, B. C., Fowell, A., Birky, M., Paabo, M., Stolte, A., Malek, D., Further Development of a Test Method for the Assessment of the Acute Inhalation Toxicity of Combustion Products, Nat. Bur. Std. (U.S.) NBSIR 82-2532, June, 1982.

9. Babrauskas, V., Upholstered Furniture Room Fires - Measurements, Comparison with Furniture Calorimeter Data, and Flashover Predictions, J. of Fire Sciences 2 , 5-19, Jan/Feb 1984 . 


\section{Base Case}

A. Double Living Room Area

B. Halve Hallway Length

C. Double Bedroom Area

D. Gypsum Board Walls

E. Double Heat of Combustion

F. Halve Heat of Combustion

G. Double Smoke Fraction

H. Halve Smoke Fraction

I. Halve Mass Loss (Burning) Rate

J. Closed Bedroom Door (Vertical Crack 1/4 in Wide Total)

\section{Input Data for the Base Case of the Example}

\section{Burning Item}

Heat of Combustion (mJ/kg)

Mass ( $\mathrm{kg}$ )

Smoke Yield $(\mathrm{g} / \mathrm{g})$

$\overline{\mathrm{LC}}_{50}(\mathrm{mg} / \ell)$

Room Dimensions

Living Room

Hall

Bedroom

Door Opening to Bedroom

Construction Material Properties

Thermal Conduçtivity ( $\mathrm{kW} / \mathrm{m}-\mathrm{K})$

Density $\left(\mathrm{kg} / \mathrm{m}^{3}\right)$

Specific Heat $(\mathrm{kJ} / \mathrm{Kg}-\mathrm{K})$

Thickness (cm)
Chair

\section{1}

28.0

0.03

32.0

Length

9 m

$9 \mathrm{~m}$

$4.9 \mathrm{~m}$
Loveseat

\section{1}

40.0

0.03

32.0

Width

$3 \mathrm{~m}$
$1.5 \mathrm{~m}$
$3.7 \mathrm{~m}$
$1 \mathrm{~m}$

Sofa

18.1

51.0

0.03

32.0

Height

$2.4 \mathrm{~m}$

$2.4 \mathrm{~m}$

$2.4 \mathrm{~m}$

$2 \mathrm{~m}$

Walls (wood) Ceiling (Gypsum)

$1.2 \times 10^{-4}$

540

2.5

$1.7 \times 10^{-4}$

960

1.1

1.59 
Table 2 - T1me to Reach Indicated Cond1tion and Percent Change from Base Case - Chair Fires

Upper Temp.

Living Room
Upper Temp.

Hall
Upper Temp.

Bedroom

\begin{tabular}{|c|c|c|c|c|c|c|c|c|c|c|c|c|}
\hline LImIt & & & 10 & ${ }^{\circ} \mathrm{C}$ & 66 & & & ${ }^{\circ} \mathrm{C}$ & 66 & & 10 & \\
\hline & Sec & $\%$ & $\mathrm{Sec}$ & $\%$ & $\mathrm{Sec}$ & $\%$ & $\mathrm{Sec}$ & $z$ & Sec & $\%$ & $\mathrm{Sec}$ & $\%$ \\
\hline Base & 106 & - & 119. & - & 124 & - & 140 & - & 149 & - & 178 & - \\
\hline A & 115 & 8 & 128 & 8 & 135 & 9 & 152 & $9^{-}$ & 162 & 9 & 199 & 12 \\
\hline B & 106 & 0 & 118 & -1 & 119 & -4 & 133 & -5 & 141 & -5 & 165 & -7 \\
\hline c & 106 & 0 & 119 & 0 & 123 & -1 & 138 & -1 & 155 & 4 & 191 & 7 \\
\hline D & 106 & 0 & 119 & 0 & 124 & 0 & 140 & 0 & 149 & 0 & 178 & 0 \\
\hline E & 17 & -84 & 106 & -11 & 109 & -12 & 123 & -12 & 129 & -13 & 149 & -16 \\
\hline$F$ & 119 & 12 & 133 & 12 & 140 & 13 & 163 & 16 & 175 & 17 & 219 & 23 \\
\hline G & 106 & 0 & 119 & 0 & 124 & 0 & 140 & 0 & 149 & 0 & 178 & . \\
\hline $\mathrm{H}$ & 106 & 0 & 119 & 0 & 124 & 0 & 140 & 0 & 149 & 0 & 178 & 0 \\
\hline I & 229 & 116 & 254 & 113 & 263 & 112 & 310 & 121 & 316 & 112 & 396 & 122 \\
\hline $\mathrm{J}$ & 28 & -74 & 66 & -45 & 79 & -36 & 119 & -15 & 199 & 34 & 290 & 63 \\
\hline
\end{tabular}

Lower Temp.

Living Room
Lower Temp. Hall
Lower Temp. Bedroom

Limit

$66^{\circ} \mathrm{C}$

$100^{\circ} \mathrm{C}$

$66^{\circ} \mathrm{C}$

$100^{\circ} \mathrm{C}$

$66^{\circ} \mathrm{C}$

$100^{\circ} \mathrm{C}$

$\begin{array}{crrrrrrrr}\text { Base } & 249 & - & 289 & - & 229 & - & 700 & - \\ \text { A } & 298 & 20 & - & - & 590 & 158 & - & - \\ \text { B } & 256 & 3 & 303 & 5 & 421 & 84 & - & - \\ \text { C } & 254 & 2 & 288 & 0 & - & - & - & - \\ \text { D } & 248 & 0 & 287 & -1 & 228 & 0 & 710 & 1 \\ \text { E } & 205 & -18 & 231 & -20 & 64 & -72 & 485 & -31 \\ \text { F } & 430 & 73 & - & - & 511 & 123 & - & - \\ \text { G } & 249 & 0 & 289 & 0 & 228 & 0 & 700 & 0 \\ \text { H } & 249 & 0 & 289 & 0 & 228 & 0 & 700 & 0 \\ \text { I } & 531 & 113 & 617 & 113 & 628 & 174 & 907 & 30 \\ \text { J } & 141 & -43 & 184 & -36 & 141 & -38 & 188 & -73\end{array}$

Interface

Living Room

Interface

Hall

Interface

Bedroom

$1.5 \mathrm{~m}$

$1.0 \mathrm{~m}$

45

$85 \quad 89$

$39-13$

$44-2$

45

$35-22$

$60 \quad 33$

450

$43-4$

$60 \quad 33$

$35-22$
146

180

135

206

146

$125-14$

$174 \quad 19$

1460

1460

20540

$111-24$
$1.5 \mathrm{~m}$

110

133

$100-9$

$112 \quad 2$

110

$\begin{array}{ll}88 & -20\end{array}$

$124 \quad 13$

1100

1100

$148 \quad 35$

$60-45$
$1.0 \mathrm{~m}$

154

180

145

202

154

$135-12$

$175 \quad 14$

1540

1540

25364

$89-42$
$1.5 \mathrm{~m}$

$1.0 \mathrm{~m}$ 
Time to Reach Ind1cated Cond1tions and Percent Change frow Base Case - Chair Fires

OD

Living Room
OD

Hall
OD

Bedroom

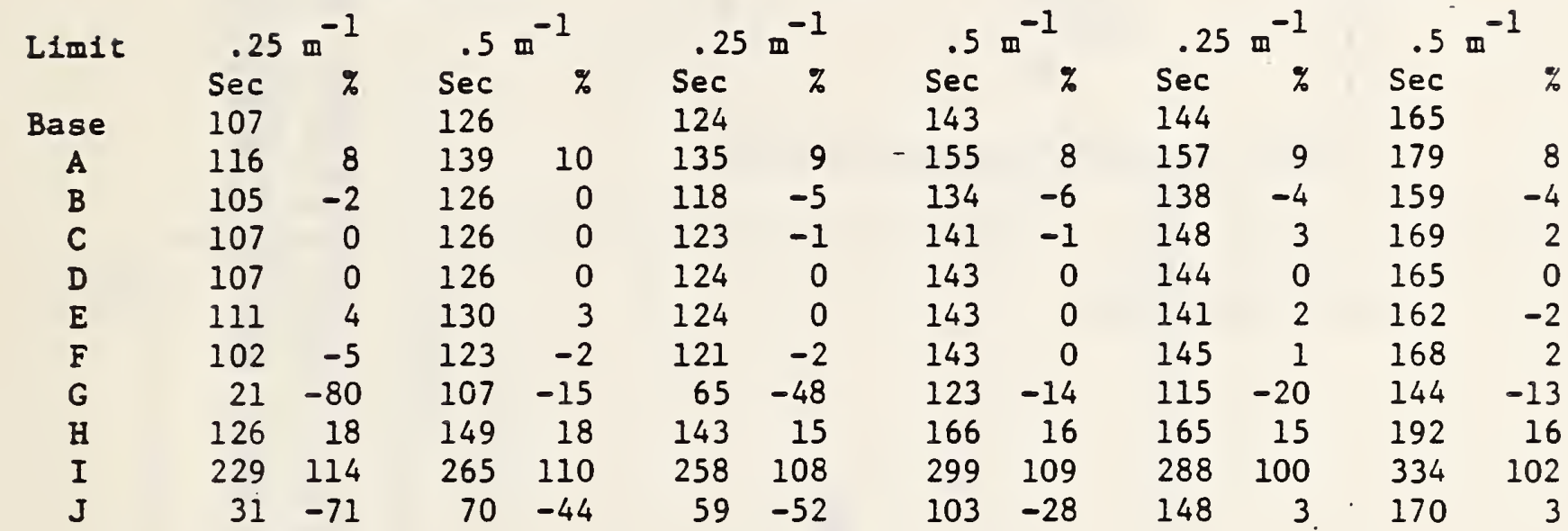

FLD Living Room

FLD Hall

\begin{tabular}{crrrrrrrrrrrrr} 
Limit & \multicolumn{2}{c}{0.5} & \multicolumn{2}{c}{1.0} & \multicolumn{2}{c}{1.5} & & 0.5 & & 1.0 & & 1.5 \\
Base & 154 & & 197 & & 235 & & 171 & & 213 & & 241 & \\
A & 172 & 12 & 225 & 14 & 258 & 10 & 189 & 11 & 233 & 9 & 265 & 10 \\
B & 154 & 0 & 197 & 0 & 232 & 4 & 167 & -2 & 211 & -1 & 237 & -2 \\
C & 153 & -1 & 193 & -2 & 228 & -3 & 165 & -4 & 202 & -5 & 233 & -3 \\
D & 154 & 0 & 197 & 0 & 135 & -43 & 171 & 0 & 213 & 0 & 241 & 0 \\
E & 163 & 6 & 216 & 10 & 251 & 7 & 175 & 2 & 217 & 2 & 244 & 1 \\
F & 149 & -3 & 183 & -7 & 215 & -9 & 170 & -1 & 208 & -2 & 236 & -2 \\
G & 154 & 0 & 197 & 0 & 235 & 0 & 171 & 0 & 213 & 0 & 241 & 0 \\
H & 154 & 0 & 197 & 0 & 235 & 0 & 171 & 0 & 213 & 0 & 241 & 0 \\
I & 330 & 114 & 440 & 123 & 512 & 118 & 370 & 116 & 450 & 111 & 506 & 110 \\
J & 127 & -18 & 159 & -19 & 183 & -22 & 139 & -19 & 162 & -24 & 179 & -26
\end{tabular}

FLD Bedroom

$\begin{array}{llll}\text { Limit } & 0.5 & 1.0 & 1.5\end{array}$

$\begin{array}{crrrrrr}\text { Base } & 197 & & 232 & & 256 & \\ \text { A } & 214 & 9 & 257 & 11 & 287 & 12 \\ \text { B } & 190 & -4 & 226 & -3 & 250 & -2 \\ \text { C } & 204 & 4 & 242 & 4 & 271 & 6 \\ \text { D } & 197 & 0 & 232 & 0 & 256 & 0 \\ \text { E } & 195 & -1 & 229 & -1 & 252 & -2 \\ \text { F } & 200 & 2 & 235 & 1 & 260 & 2 \\ \text { G } & 197 & 0 & 232 & 0 & 256 & 0 \\ \text { H } & 197 & 0 & 232 & 0 & 256 & 0 \\ \text { I } & 401 & 104 & 471 & 103 & 519 & 103 \\ \text { J } & 205 & 4 & 236 & 2 & 257 & 0\end{array}$




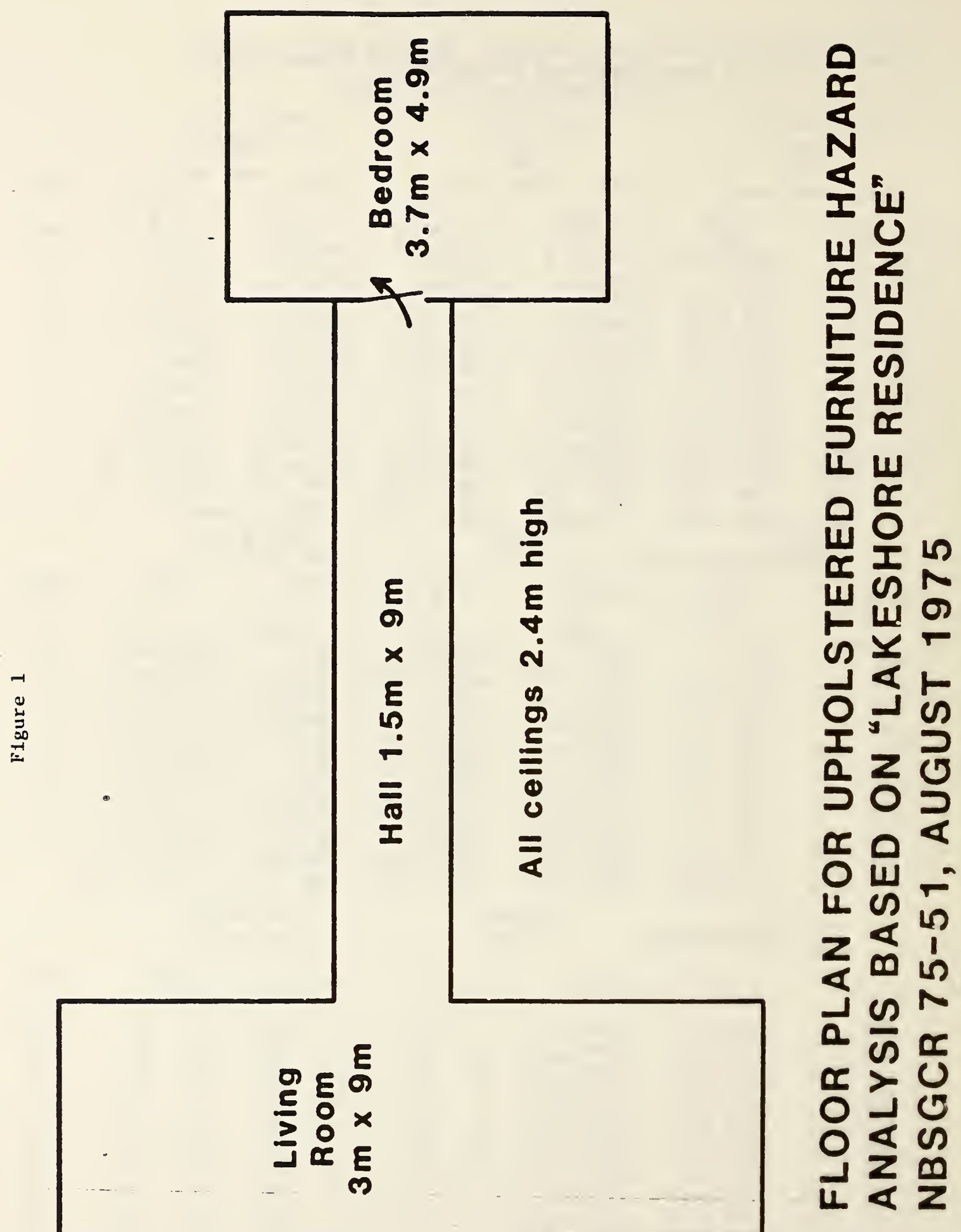




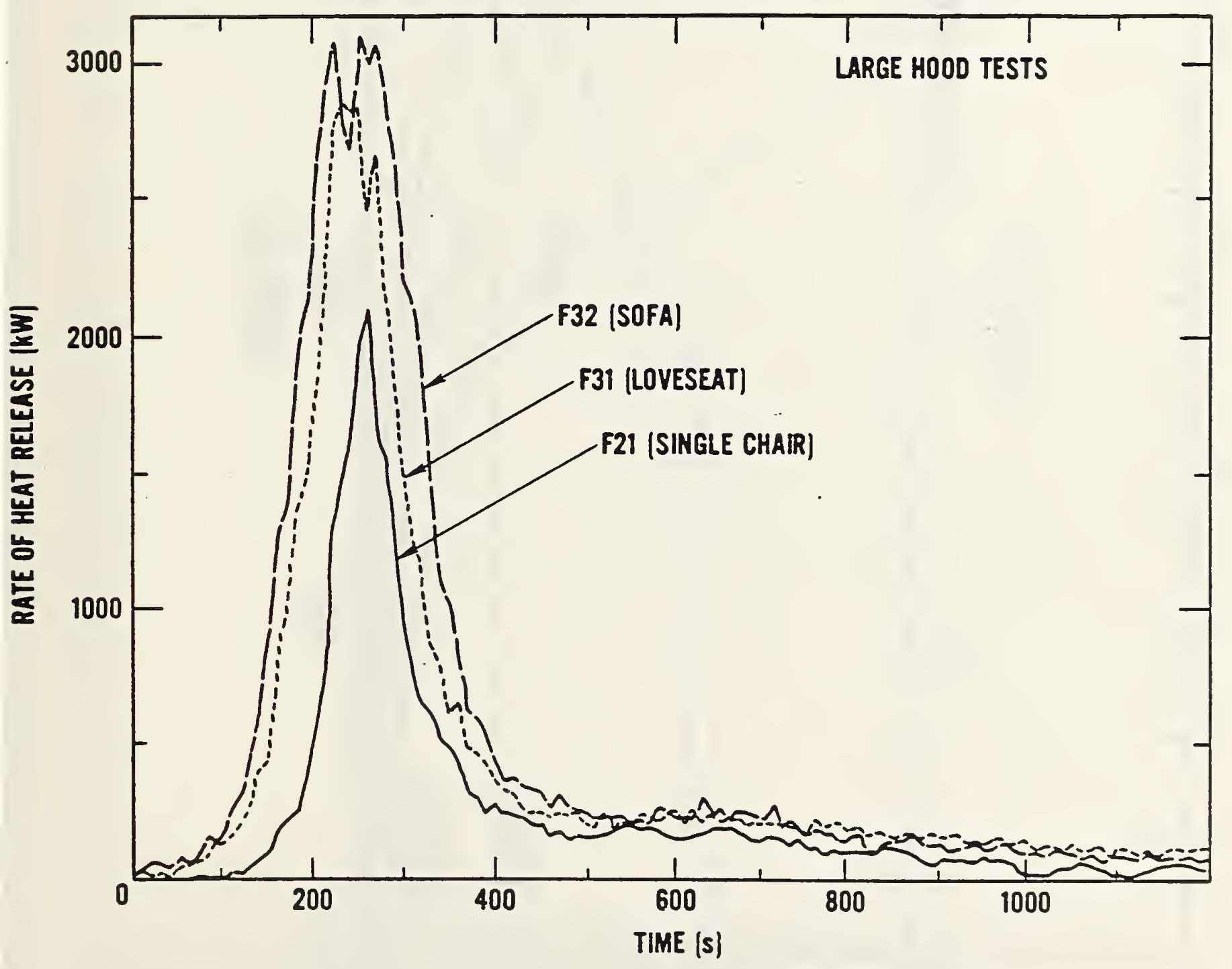

Figure 2. Heat release rates for the three upholstered furniture items. 


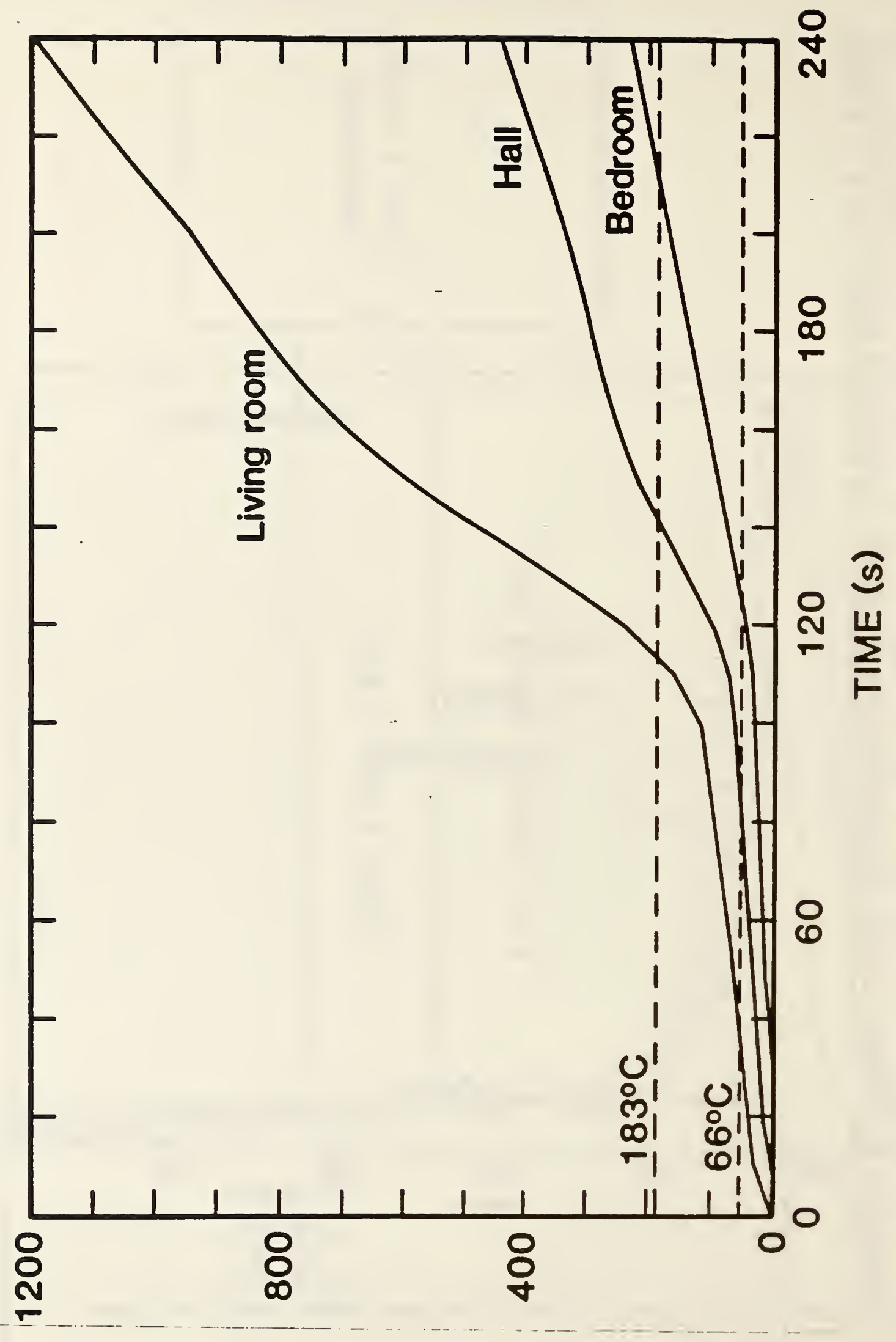

(כo) $\exists \forall n \perp \forall \forall \exists d W \exists \perp \forall \exists \wedge \forall\urcorner \quad \forall \exists d d n$

Figure 3. Example plot of upper layer temperature vs. time for base case, loveseat fire. 


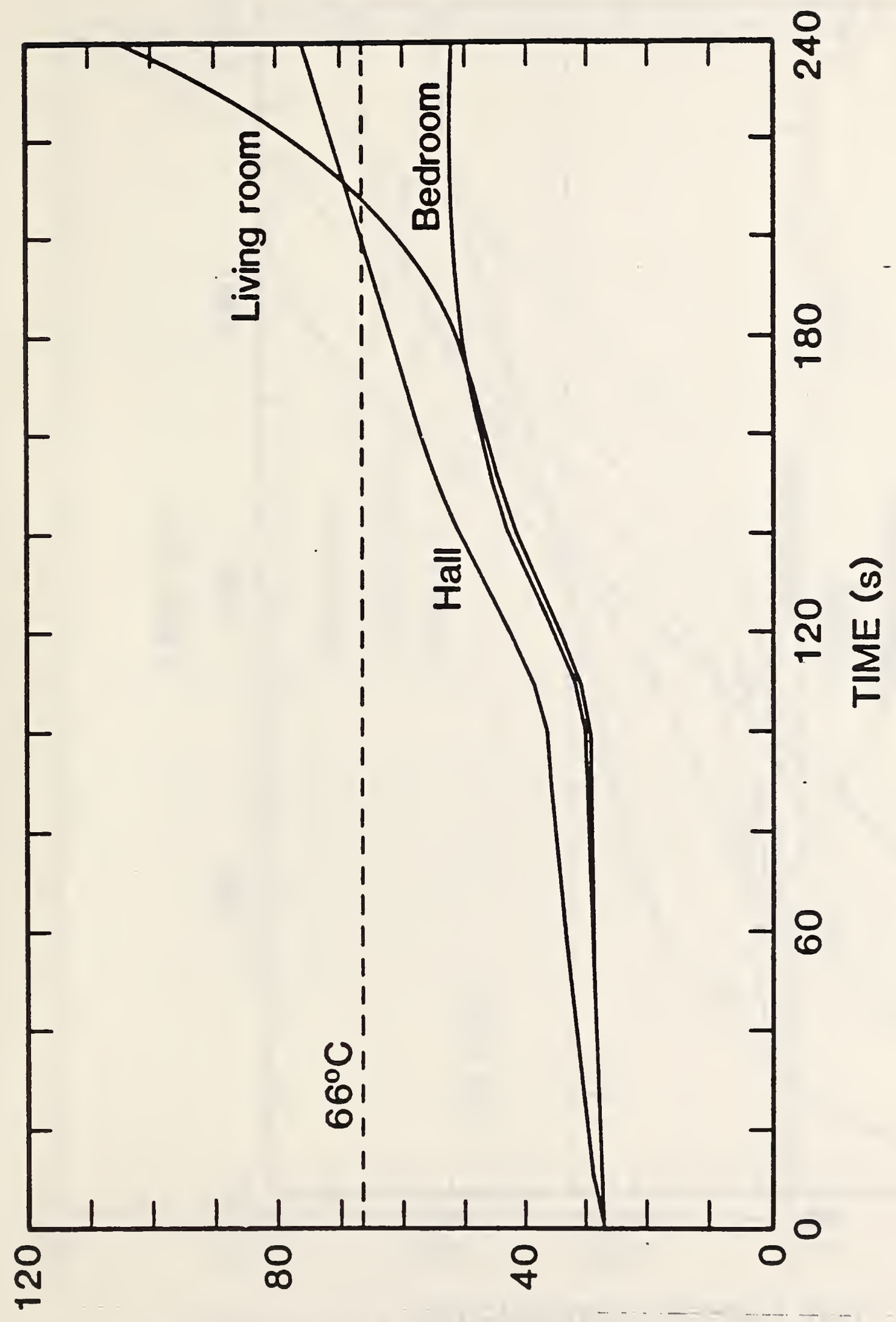

(כo) $\exists y \cap \perp \forall \forall \exists d W \exists \perp$ $\forall \exists \wedge \forall\urcorner \quad \forall \exists M O\urcorner$

Figure 4. Example plot of lower layer temperature vs. time for base case, loveseat fire. 


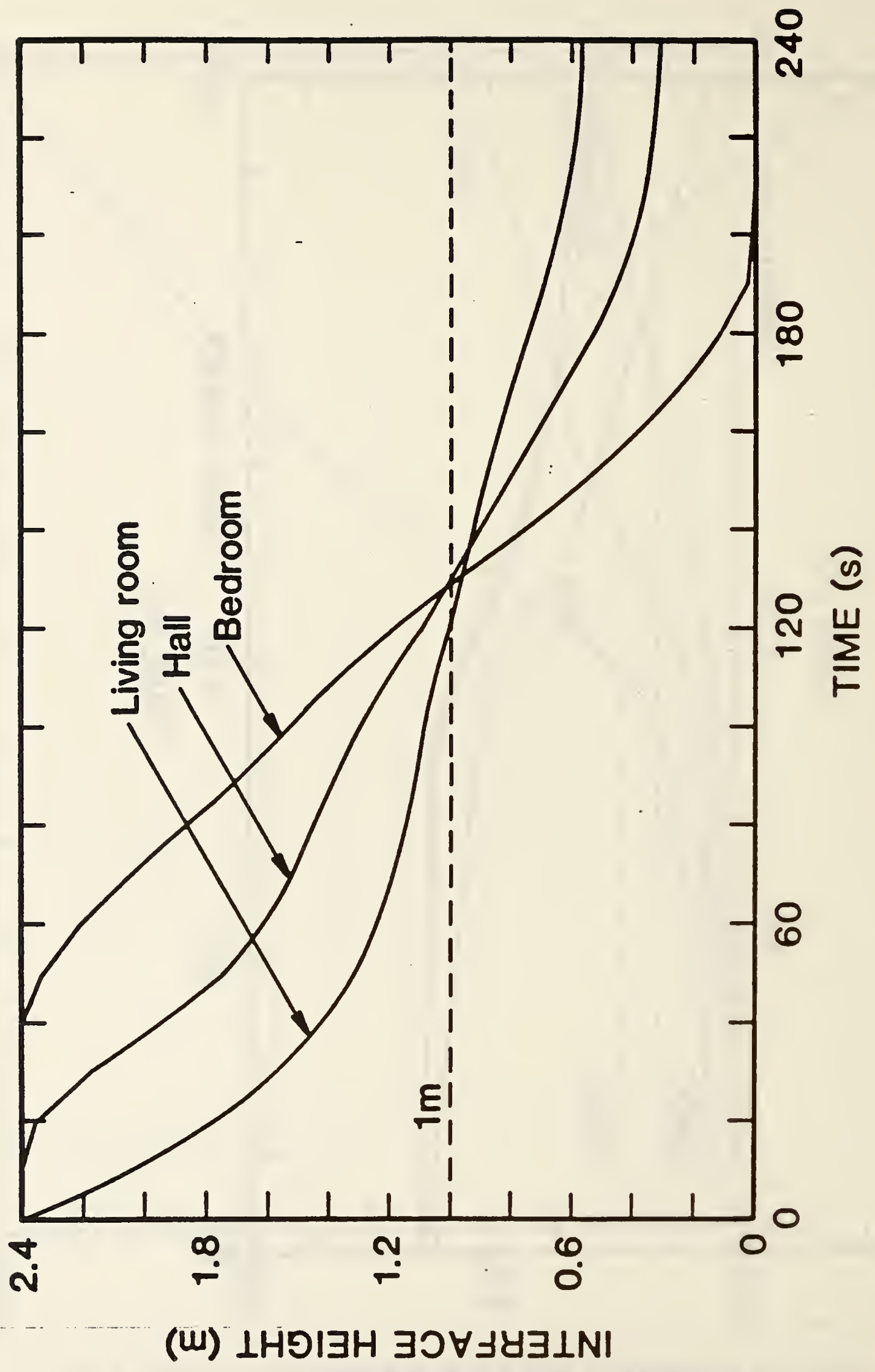

Figure 5. Example plot of interface height vs. time for base case, loveseat fires. 


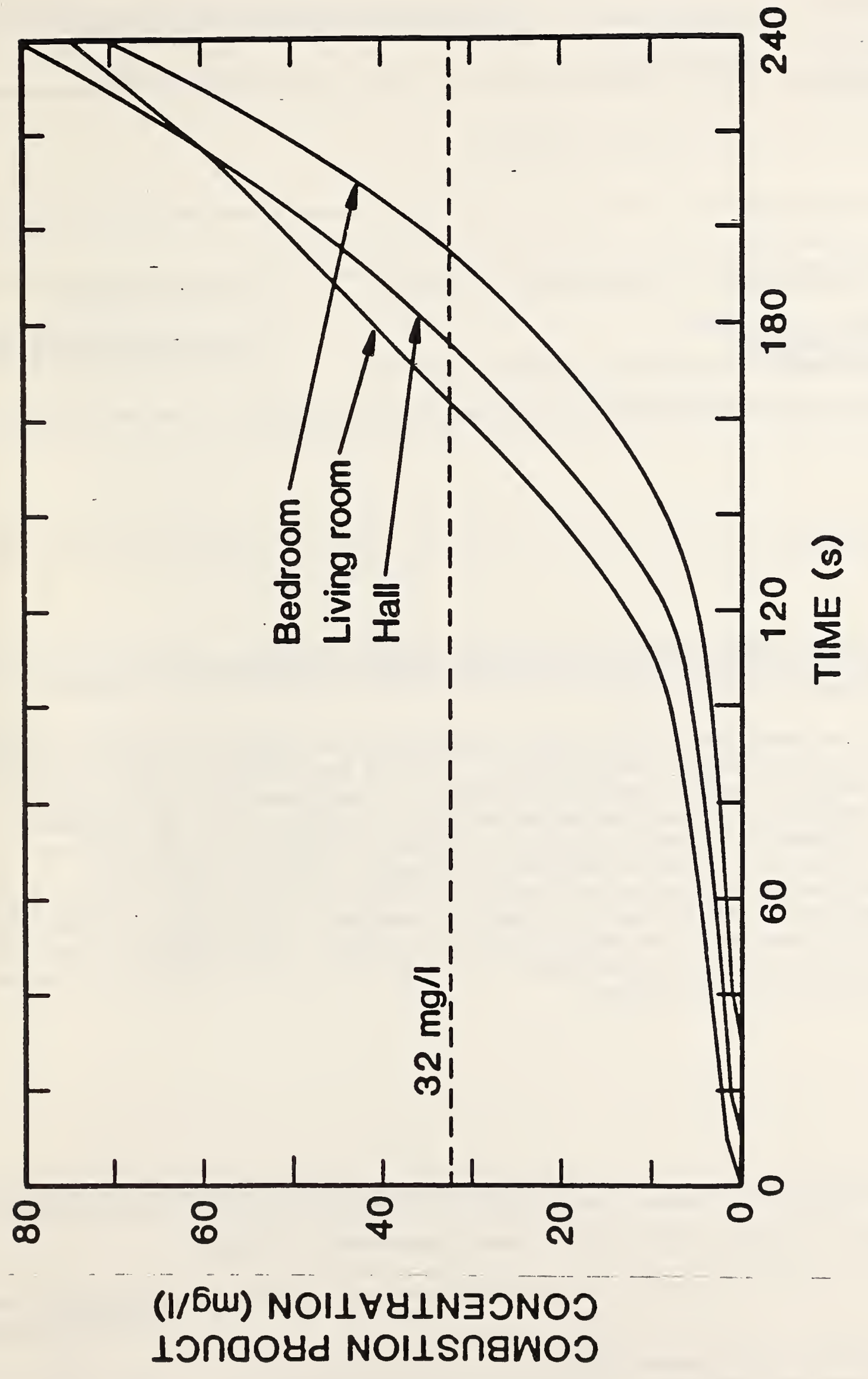

Figure 6. Example plot of upper layer toxicity concentration vs. time for base case, loveseat fire. 
NBS-114A (REV. 2-8C)

U.S. OEPT. OF COMM.

BIBLIOGRAPHIC DATA

SHEET (See in struction s)
1. PUBLICATION OR REPORT NO.

NBSIR-86/3349
2. Performing Organ. Report No J. Publication Date

March 1986

4. TITLE AND SUBTITLE

An Introduction to Fire Hazard Modeling

5. AUTHOR(S)

Richard W. Bukowski

6. PERFORMING ORGANIZATION (If joint or other than NBS, see instructions)

7. ContracUGrant No.

NATIONAL BUREAU OF STANDARDS

DEPARTMENT OF COMMERCE

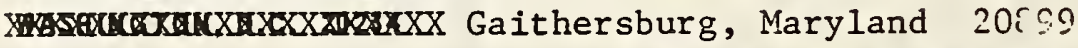

8. Type of Report \& Period Covered

9. SPONSORIHG ORGANIZATION NAME AND COMPLETE ADDRESS (Street, City, Stote, ZIF)

10. SUPPLEMENTARY NOTES

Document describes a computer program; SF-185. FIPS Software Summary, is attached.

11. ABSTRACT (A 200-word or less foctual summary of most significant information. If document includes a significant

bibliogrophy or literoture survey. mention it here)

An overview of the development and current capabilities of predictive methods for fire hazard analysis is provided. This includes a range of methods from simple, algebraic equations to complex, computer simulation models. In each case the form, major simplifying assumptions, calculated parameters, and limitations will be discussed. The specific application of these predictive methods to hazard analysis, and the availability of the data resources necessary to conduct a hazard analysis is described. Information on the use of a number of available models, with particular emphasis on those which can be used on desk-top computers, is provided. A discussion of the predictive accuracy of selected models is, included. Some examples of hazard analyses using these methods are presented. This report is an overview of the author's previous publications on the subject.

12. KEY WORDS (Six to twelve entries; alphabetical order; capitalize only proper names: and separate key words ty semicolons) computer models; equations; fire models; hazard assessment; toxicity

13. AVAILABILITY

X] Unlimited

For Official Distribution. Do Not Release to NTIS

$\square$ Order From Superintendent of Documents, U.S. Government Printing Office, Washington, D.C. 20402.

[X] Order From National Technical Information Service (NTIS), Springfield, VA. 2216I
14. NO. OF

PRINTEO PAGES

102

15. Price

$\$ 16.95$ 

$-$ 